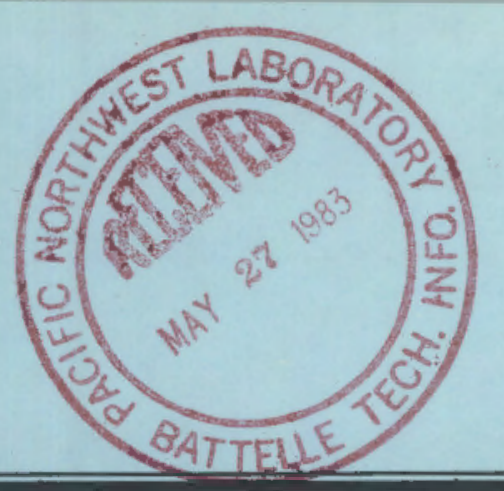

PNL -4516 I-

NUREG/CR-3016 PNL-4516

\title{
Evaluation of the Split-H Approach to Modeling Non-Buoyant Releases from Vent Stacks
}

Prepared by J. V. Ramsdell

Pacific Northwest Laboratory

Operated by

Battelle Memorial Institute

Prepared for

U.S. Nuclear Regulatory

Commission 


\section{NOTICE}

This report was prepared as an account of work sponsored by an agency of the United States Government. Neither the United States Government nor any agency thereof, or any of their employees, makes any warranty, expressed or implied, or assumes any legal liability of responsibility for any third party's use, or the results of such use, of any information, apparatus, product or process disclosed in this report, or represents that its use by such third party would not infringe privately owned rights.

\section{Availability of Reference Materials Cited in NRC Publications}

Most documents cited in NRC publications will be available from one of the following sources:

1. The NRC Public Document Room, 1717 H Street, N.W. Washington, DC 20555

2. The NAC/GPO Sales Program, U.S. Nuclear Regulatory Commission, Washington, DC 20555

3. The National Technical Information Service, Springfield, VA 22161

Although the listing that follows represents the majority of documents cited in NRC publications, it is not intended to be exhaustive.

Referenced documents available for inspection and copying for a fee from the NRC Public Document Room include NRC correspondence and ir.terna! NRC memoranda; NRC Office of Inspection and Enforcement bulletins, circulars, information notices, inspection and investigation notices; Licensee Event Reports; vendor reports and correspondence; Commission papers; and applicant and licensee documents and correspondence.

The following documents in the NUREG series are available for purchase from the NRC/GPO Sales Program: formal NAC staff and contractor reports, NRC-sponsored conference proceedings, and NRC booklets and brochures. Also available are Regulatory Guides, NRC reguiations in the Code of Federal Regulations, and Nuclear Regulatory Commission /ssuances.

Documents available from the National Technical Information Service include NUREG series reports and technical reports prepared by other federal agencies and reports prepared by the Atomic Energy Commission, forerunner agency to the Nuclear Regulatory Commission.

Documents available from public and special technical libraries include alt open literature items, such as books, journal and periodical articles, and transactions. Federal Register notices, federal and state legislation, and congressional reports can usually be obtained from these libraries.

Documents such as theses, dissertations, foreign reports and transiations, and non-NRC conference proceedings are available for purchase from the organization sponsoring the publication cited.

Single copies of NRC draft reports are available free upon written request to the Division of Technical Information and Document Control, U.S. Nuclear Regulatory Commission, Washington, DC 20555.

Copies of industry codes and standards used in a substantive manner in the NRC regulatory process are maintained at the NRC Library, 7920 Norfolk Avenue, Bethesda, Maryland, and are available there for reference use by the public. Codes and standards are usually copyrighted and may be purchased from the originating organization or, if they are American National Standards, from the American National Standards Institute, 1430 Broadway, New York, NY 10018. 


\section{Evaluation of the Split-H Approach to Modeling Non-Buoyant Releases from Vent Stacks}

Manuscript Completed: December 1982

Date Published: April 1983

Prepared by

J. V. Ramsdell

Pacific Northwest Laboratory

Richland, WA 99352

\section{Prepared for}

Division of Systems Integration

Office of Nuclear Reactor Regulation

U.S. Nuclear Regulatory Commission

Washington, D.C. 20555

NRC FIN B2514 


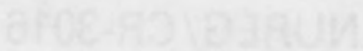



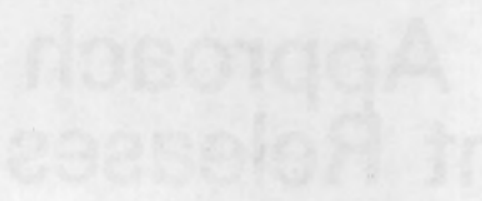




\section{ABSTRACT}

Position C.2.b of Regulatory Guide 1.111 describes an approach to modeling the diffusion of effluents from roof top vents and short stacks using an elevated plume model under some conditions and using a ground-level source building wake model under other conditions. The approach is sometimes called a Split-H model. This report: presents the results of an evaluation of the technical basis for and utility of the concept behind the Split-H model, outlines the development of an upgraded Split-H model using existing plume rise and building wake models, compares ground-level, annual average concentrations estimated using the upgraded model with those estimated using the Regulatory Guide Split-H model and a ground-level building wake model, and discusses alternatives to the Regulatory Guide position that the NRC may wish to consider. Concentration comparisons are made using model results for meteorological data from 18 nuclear power plant sites.

Differences between annual average, ground-level concentration estimates made using the upgraded Split-H model and those made with the other two models for the same meteorological conditions are a function of the distance from the source and stack parameters including exit velocity and diameter. They are greatest near the source. For example, at a distance of $400 \mathrm{~m}$ and a stack flow rate of $31.4 \mathrm{~m}^{3} / \mathrm{s}$, the average ratio between the upgraded model and the corresponding ground-level release model concentrations ranges from about 0.6 for a stack exit vertical velocity of $5 \mathrm{~m} / \mathrm{s}$ to about 0.2 for an exit velocity of $20 \mathrm{~m} / \mathrm{s}$. When compared with concentrations estimated using the Regulatory Guide Split-H model, upgraded Split-H model concentration estimates at $400 \mathrm{~m}$ range from about a factor of 5 larger for low vertical velocity releases to about a factor of 3 larger for high vertical velocity releases. Individual differences of an order of magnitude or more were found in both comparisons.

On a climatological basis, the reduction of ground-level concentrations that results from the use of the upgraded Split-H model in place of the groundlevel release model is described by an exponential function of the ratio between the average wind speed in a sector and the vertical velocity of the release. The decay parameter in the relationship is a function of the distance from the source and the flow rate in the stack. It ranges from about -0.1 for long ranges $(6400 \mathrm{~m})$ and $10 \mathrm{w}$ flow rates $\left(15.7 \mathrm{~m}^{3} / \mathrm{s}\right)$ to about -0.8 for short ranges $(400 \mathrm{~m})$ and high flow rates $\left(125.7 \mathrm{~m}^{3} / \mathrm{s}\right)$. 



\section{ACKNOWLEDGMENTS}

Many people have contributed to the preparation of this report. The efforts of Clifford Glantz and the NRC Technical Monitor, James Fairobent are particularly noteworthy. Cliff assisted in the preparation of the data set used in the model comparisons, made the computer runs, and assisted in the analysis of the model output. Jim contributed to the work by providing encouragement and by highlighting the aspects of the work that are of particular interest to the NRC. Others, including Chris Doran, Bill Sandusky, Lin Lindsey and Jerry Allwine at PNL and Earl Markee and Irwin Spickler at the NRC, contributed to the work by providing incisive comments. All of these efforts are greatly appreciated. 



\section{CONTENTS}

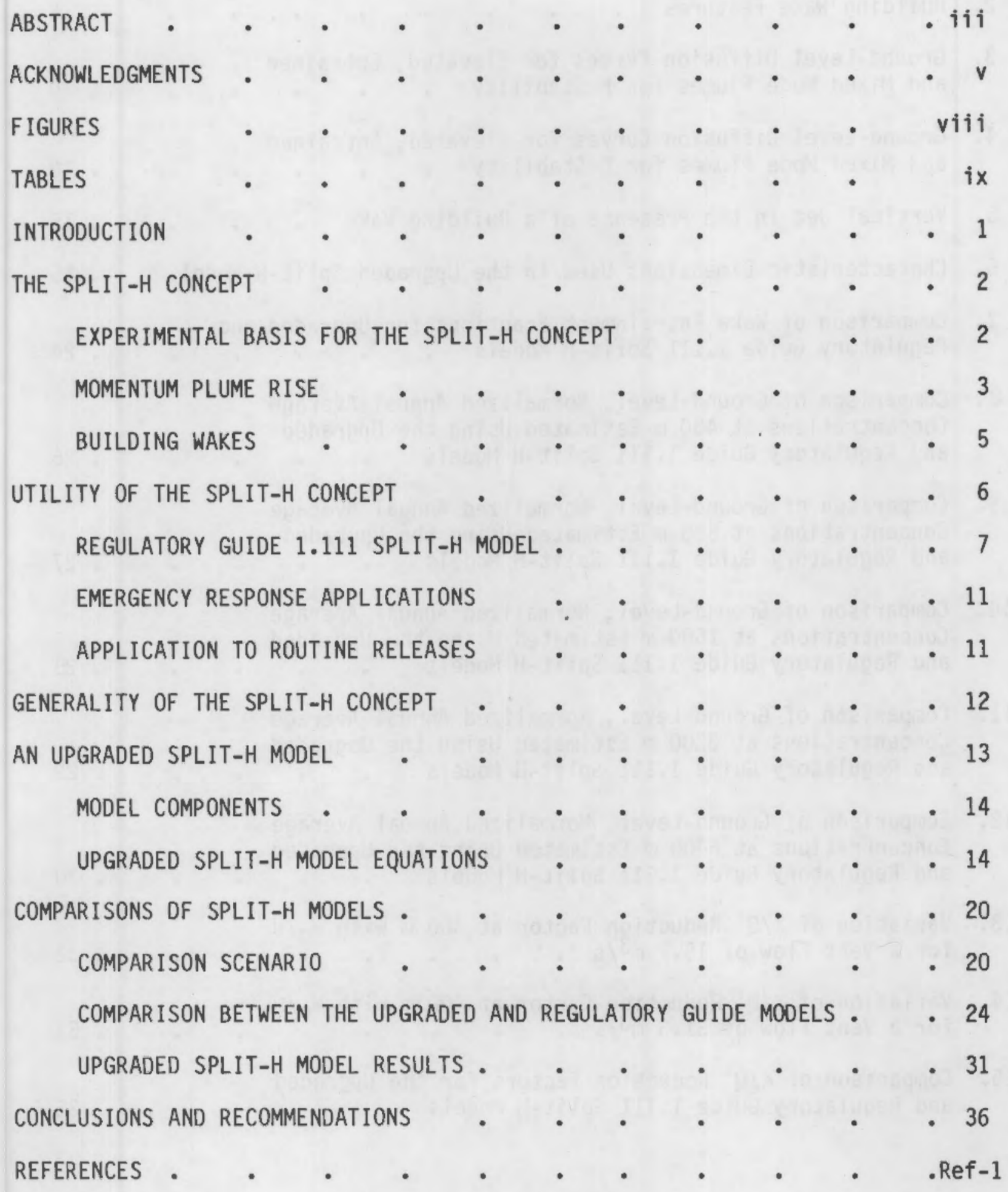




\section{FIGURES}

1. Basic Features of a Vertical Jet . . . . . . . 4

2. Building Wake Features . . . . . . . . . 5

3. Ground-Level Diffusion Curves for Elevated, Entrained .
and Mixed Mode Plumes for F Stability . . . 9

4. Ground-Level Diffusion Curves for Elevated, Entrained and Mixed Mode Plumes for C Stability . . . . . . 10

5. Vertical Jet in the Presence of a Building Wake . . . 15

6. Characteristic Dimensions Used in the Upgraded Split-H Model. 15

7. Comparison of Wake Entrainment Fractions for Upgraded and Regulatory Guide 1.111 Split-H Models . . . . . 24

8. Comparison of Ground-Level, Normalized Annual Average Concentrations at $400 \mathrm{~m}$ Estimated Using the Upgraded and Regulatory Guide 1.111 Split-H Models . . . . 26

9. Comparison of Ground-Level, Normalized Annual Average Concentrations at $800 \mathrm{~m}$ Estimated Using the Upgraded and Regulatory Guide 1.111 Split-H Models . . . . 27

10. Comparison of Ground-Level, Normalized Annual Average Concentrations at $1600 \mathrm{~m}$ Estimated Using the Upgraded and Regulatory Guide 1.111 Split-H Models

11. Comparison of Ground-Level, Normalized Annual Average Concentrations at $3200 \mathrm{~m}$ Estimated Using the Upgraded and Regulatory Guide 1.111 Split-H Models

12. Comparison of Ground-Level, Normalized Annual Average Concentrations at $6400 \mathrm{~m}$ Estimated Using the Upgraded and Regulatory Guide 1.111 Split-H Models . . . . . 30

13. Variation of $X / Q^{\prime}$ Reduction Factor at $400 \mathrm{~m}$ with $W_{0} / \bar{U}$ for a Vent Flow of $15.7 \mathrm{~m}^{3} / \mathrm{s}$. . . . . . . 32

14. Variation of $X / Q^{\prime}$ Reduction Factor at $400 \mathrm{~m}$ with $W_{0} / \bar{U}$ for a Vent Flow of $31.3 \mathrm{~m}^{3} / \mathrm{s}$. . . . . . 33

15. Comparison of $X / Q^{\prime}$ Reduction Factors for the Upgraded and Regulatory Guide 1.111 Split-H Models 


\section{$\underline{\text { TABLES }}$}

1. Meteorological Data Set Used in Model Comparisons . . . 22

2. Maximum, Geometric Mean and Minimum Ratios of Annual Average Concentrations for an Effluent Vertical Velocity of $10 \mathrm{~m} / \mathrm{s}$. 31

3. Decay Parameter Values for the $X / Q^{\prime}$ Reduction Factor . . 34 



\section{INTRODUCTION}

In October 1975, the results of a series of diffusion tests at the Millstone Nuclear Power Station were published by the Atomic Industrial Forum (Johnson et al. 1975). The report contains a recommendation that diffusion from roof top vents and stacks be treated with what was called a "Split-H" model. In the Split-H model, releases are treated as elevated under certain conditions, as ground level within the building wake under other conditions, and as a combination of elevated and ground level under an intermediate set of conditions. The Nuclear Regulatory Commission adopted a Split-H type approach as a step toward more realism in modeling dispersion of routine releases from nuclear power plants in 1977. This approach, contained in Position C.2.b of the Regulatory Guide 1.111, is a model of the form recommended by Johnson et al. but having different coefficients. Subsequently, Thuillier and Mancuso (1980) published the results of a 1978 set of diffusion tests conducted at the Duane Arnold Energy Center. Application of the Millstone Split-H model at Duane Arnold did not give good estimates of the ground level concentrations when tracers were released from roof top vent stacks. The NRC staff is reconsidering its regulatory position because of the results of the Duane Arnold experiments.

This report provides the staff with information for use in reevaluation of the Split-H concept and the specific model contained in Position C.2.b of Regulatory Guide 1.111. The scope of the investigation upon which the report is based was limited to a literature search and an evaluation of the information contained in the literature. It did not include a reanalysis of the data described in the literature or the collection of new data sets.

Five specific goals were defined within the overall objective. These goals are:

1. to examine the basic validity of the Split-H concept for evaluating releases from nuclear reactor building vents

2. to evaluate the utility of the Split-H concept as applied to modeling diffusion of routine and abnormal vent releases

3. to develop an upgraded Split-H model and the criteria needed for its application, if appropriate

4. to compare the Split-H model in Position C.2.b of Regulatory Guide 1.111 with the upgraded model

5. to recommend changes to Position C.2.b and research related to Split-H models and the criteria used in applying them to evaluation of releases from nuclear power plants. 
It is clear from the list that the goals are limited to an evaluation of the Split-H concept and models, and do not include an evaluation of the basic diffusion models used for elevated or ground level sources. Further, the concept and models are evaluated only for application to vertical releases from vents and stacks at or above roof top levels.

\section{THE SPLIT-H CONCEPT}

Culkowski (1967) describes three different modes for the interaction between plumes released near the roofs of buildings and the building wakes. When the wind is strong, plumes become entrained in the near wakes of buildings, coming to the ground immediately and mixing through a relatively large volume on the lee side of the buildings. When the wind is light, plumes rise well above buildings and disperse as if released from isolated tall stacks. At intermediate wind speeds, plumes are deflected toward the ground by the flow over buildings. Under these conditions material in plumes reaches the ground sooner than it would have had it been released from an isolated stack of the same height, but little, if any, of the material enters the near wake just to the lee of the buildings. Plumes frequently shift from one mode to another. Split-H models are an attempt to incorporate the effects of this dynamic plume behavior in estimates of average ground level concentrations.

\section{EXPERIMENTAL BASIS FOR THE SPLIT-H CONCEPT}

Early experimental work related to the Split-H concept includes the wind tunnel and field studies of Davies and Moore (1964) and Martin (1965), and the field studies of Munn and Cole (1967). These studies identified the ratio between the vertical velocity of the vent exhaust and the horizontal wind speed as an important factor controlling the modes of plume interaction with building wakes. Critical wind speeds for various modes of interaction were defined on a site-by-site basis. The wind tunnel studies of Meroney, Cermak and Chaudhry (1968) demonstrated that the frequency with which the mode of interaction changed was also a function of wind speed.

Lawson (1967) used the data of Munn and Cole (1967) to develop a mathematical model describing the differences in expected ground-level concentrations in plumes released near building tops as a function of wind speed. Rodliffe and Fraser (1971) analyzed 41 Ar data collected in the vicinity of the Hinkley Point "A" Nuclear Power Station in Great Britain, and developed a model that explicitly included the Split-H concept. In their model, the plume was assumed to be elevated if the wind speed were below a critical value, and at ground level if the wind speed were above it. The basic model, using only mean speeds was compared with a model in which the state of the plume was determined from the instantaneous wind speed, assuming a mean and a Gaussian distribution for wind speed fluctuations. The latter of these models is, in essence, closely related to the $\mathrm{Split}-\mathrm{H}$ model recommended by Johnson et al. 
(1975) and the one given in Regulatory Guide 1.111. Rodliffe and Fraser explicitly identify a responsible physical mechanism and the assumptions involved in differentiating between elevated and ground-level plumes, whereas Johnson et al. and Regulatory Guide 1.111 Position C.2.b simply give empirical methods for incorporating the variation of the plume between interaction modes.

The analysis of Rodliffe and Fraser goes beyond the identification of a single critical wind speed. It shows that the transition takes place over a range of speeds and that the range is a function of wind direction. Smoke tests conducted at the Peach Bottom Power Atomic Station (Philadelphia Electric 1974) also show that the wind direction can have a significant effect on the wind speeds at which plumes change from elevated to ground level. The observed effects of wind direction are evidence that the downwash of plumes from vents and short stacks is a function of building geometry as well as the ratio between the vertical velocity of the stack effluent and the horizontal wind speed. Further evidence along these lines is apparent when the differences in critical wind speeds from location to location are considered.

The Split-H concept is, then obviously, a method of describing a relationship between plume rise and a building wake. In the present case, plume rise is considered to be a function only of the momentum of the vent or stack effluent and the state of the atmosphere. Plume rise due to a difference in density between the effluent and the atmosphere is assumed to be negligible. The rise required for a plume to behave as a release from an isolated stack is a function of the vertical extent of the effects of a building on airflow. It is reasonable, therefore, to conclude the introduction to the Split-H concept with brief discussions of momentum-dominated plume rise and building wakes.

\section{MOMENTUM PLUME RISE}

Momentum-dominated plumes are called jets in the fluid mechanics literature. Mathematical descriptions of horizontal jets are found in texts such as Hinze (1957), Bird, Stewart and Lightfoot (1960), Schlichting (1968), and Batchelor (1970). They do not discuss vertical jets. The early literature on the rise of vertical jets is summarized by Briggs (1969 and 1975).

Figure 1 illustrates the important features of a vertical jet. The jet enters the atmosphere with momentum proportional to the square of the product of the effluent velocity and the inside radius of the vent or stack. The velocity shear between the motion of the jet and the atmosphere causes ambient air to be entrained into the jet. This results in an increase in mass of the jet as it rises and a corresponding increase in its cross-sectional area. The vertical motion of the plume slows as mass is added and as a result of the work required to lift the plume. Meanwhile, the momentum of the entrained air and force applied by the horizontal wind quickly give the plume a horizontal component of momentum equal to that of the free air. When the jet has assumed 


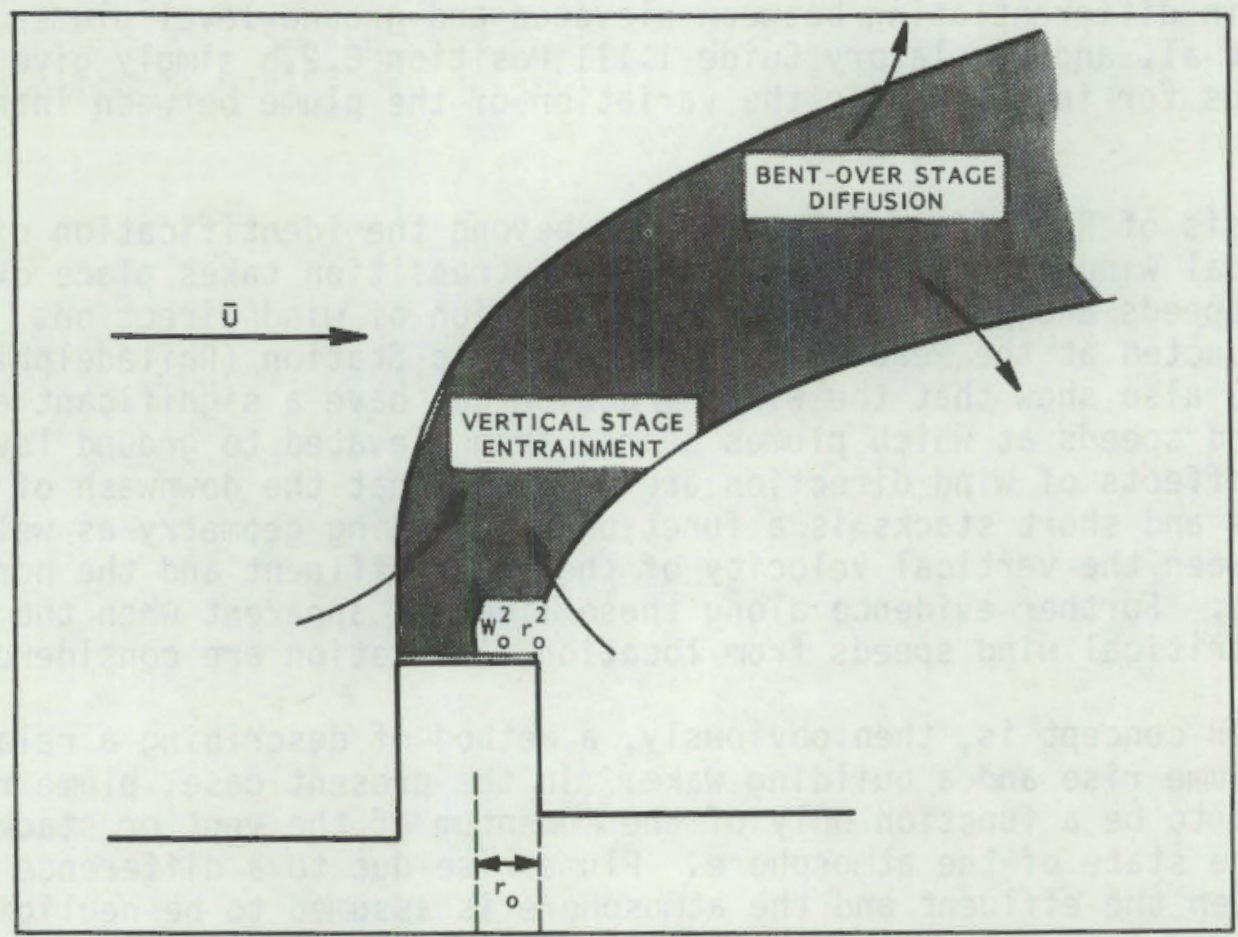

FIGURE 1. Basic Features of a Vertical jet

the horizontal motion of the free air it is referred to as being in the bentover stage. During initial rise, entrainment is the dominant factor in radial spread of the jet; in the bent-over stage, diffusion is the dominant factor.

Estimation of the rise of a jet from the equations of motion, the conservation of energy and the conservation of mass is beset with the closure problem encountered in many areas of fluid dynamics. There are more unknowns than there are independent equations. As a result, it is necessary to make an assumption if the equations are to be solved numerically, or to approach the problem in a different manner. Two alternative methods of estimating plume rise have been used extensively. The first of these methods is through empirical equations derived from data, and the second is through the use of models derived using dimensional analysis with constants determined from data. The Holl and plume rise formula (U.S. Weather Bureau 1953) is an example of the empirical approach, while the formulae of Briggs (1969) and Scorer (1958 and 1959) are examples of the results of the dimensional analysis approach. 


\section{BUILDING WAKES}

Hosker (1981) presents an extensive review of the literature on building wakes. In general, it contains the results of wind tunnel studies. Comparisons between the relatively few field studies of building wakes and similar wind tunnel studies do not yield consistent results. Frequently details of the wake structure found in wind tunnel simulations are not found in the full-scale studies. The reasons for the discrepancy have not been established. The features found in the wind tunnel may not exist in the atmosphere due to conditions that are not modeled in the wind tunnel, or the measurements in the full-scale studies may not be sufficiently detailed to identify the features. In any event, it is necessary to rely on wind tunnel results for a basic definition of the structure of building wakes.

Hanna, Briggs and Hosker (1982) and Hosker (1981) present descriptions of the wake in the vicinity of a two-dimensional building that are based on the wind tunnel studies of Wilson (1979a and b). The essential features of the descriptions are shown in Figure 2.

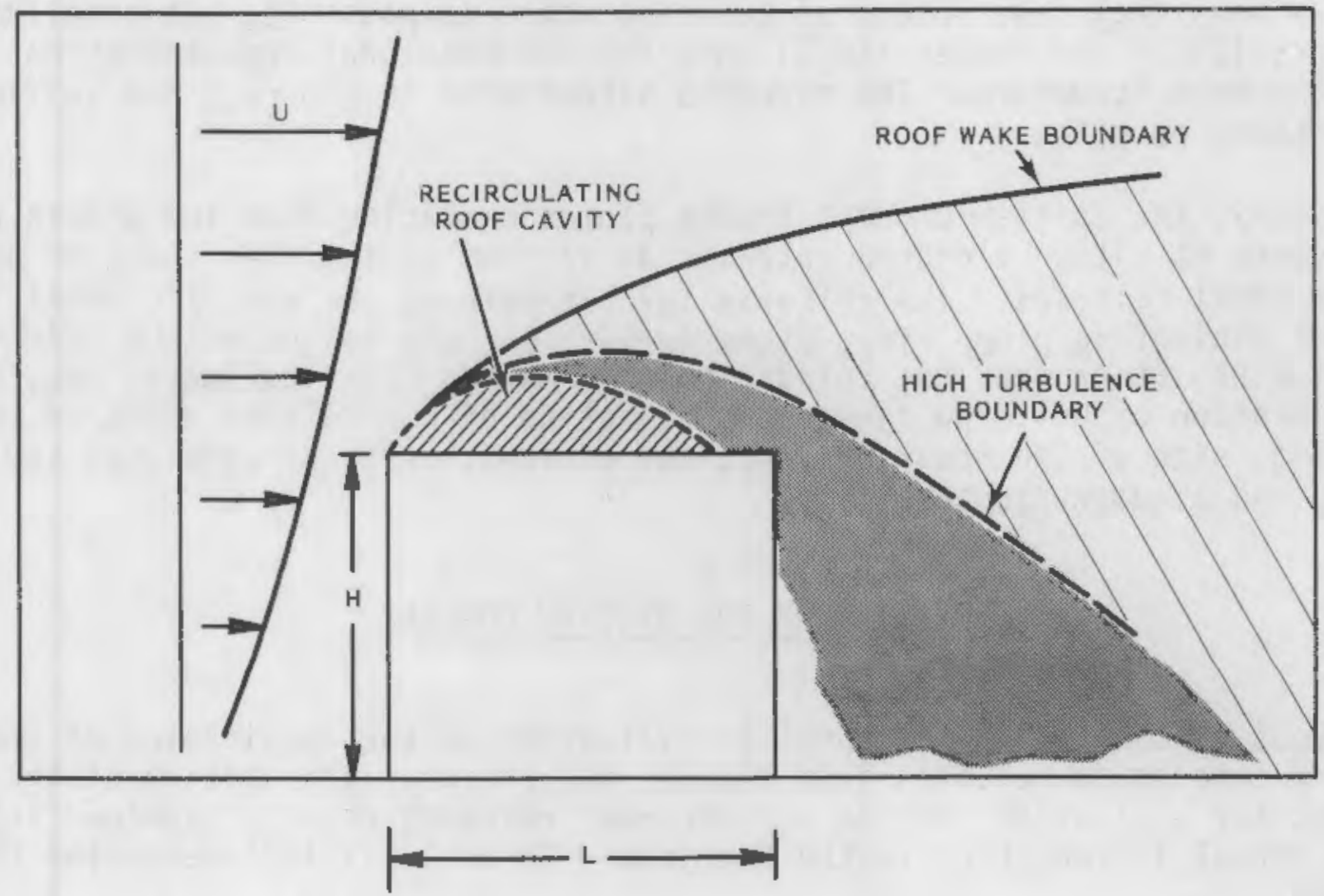

FIGURE 2. Building Wake Features

Given an approaching air flow in which the speed increases with height and a rectangular building, with height $H$, along wind dimension $L$, and cross wind most zone is the recirculating cavity, consists of three zones. The innerwake, and the outer zone is the roof , the next zone is the high turbulence 
limited to an area of the roof, or it may extend to ground level in the lee of the building. Within the cavity there tends to exist a closed circulation, the lower portion of which flows upstream relative to the free stream flow. Although the circulation in the cavity tends to be closed, there is some exchange of air between the cavity and the high turbulence zone. The airflow in the high turbulence zone is generally downward and away from the building. Material released in this zone will mix to the surface rapidly. Finally in the roof wake zone the flow is generally characteristic of conditions upwind of the building with respect to turbulence, but it is deflected toward the ground in the lee of the building. The downward deflection of the flow in the roof wake is less pronounced than in the high turbulence zone.

Wilson (1979a and b) defines the upper boundaries of the zones in terms of a building scale length estimated from the building height and crosswind dimension and the distance from the upwind building face. The zone boundaries start along the edge between the upwind building face and the roof, and they are approximately coincident from that point to the point where the cavity reaches its maximum vertical extent. Wilson gives a relationship that may be used to determine if the recirculation zone extends beyond the roof to the leeward side of the building.

Three-dimensional description of building wakes is possible, but complicated. Halitsky (1968) and Hosker (1981) show three-dimensional representations of building wake structure. The concepts 111 ustrated in Figure 2 are sufficient for present purposes.

In summary, the Split-H concept treats plumes emanating from low stacks and roof vents as either elevated releases as if from an isolated stack or as ground level releases. The criteria for determining the specific condition involve estimating plume rise, plume spread, and the height of the effects of buildings at or near the release point. Making these estimates requires consideration of building dimensions, location of the release point on the building, size of the stack or vent, the effluent vertical velocity, the wind speed, and atmospheric stability.

\section{UTILITY OF THE SPLIT-H CONCEPT}

The focus of the report now turns to evaluation of the application of the Split-H concept to releases from nuclear facilities. The utility of the concept for evaluating routine and abnormal releases uses is examined following a formal introduction to the Regulatory Guide 1.111 implementation of the concept. 


\section{REGULATORY GUIDE 1.111 SPLIT-H MODEL}

According to the Split-H concept, the observed average concentration, normalized for release rate and wind speed, is a linear combination of the normalized concentrations for elevated and ground level plumes

$$
\left(\frac{X \bar{U}}{Q^{\top}}\right)_{\text {obs }}=M\left(\frac{X \bar{U}}{Q^{\top}}\right)_{\text {entr }}+(1-M)\left(\frac{X \bar{U}}{Q^{\top}}\right)_{\text {elev }}
$$

where $M$ represents the fraction of the time that the plume is entrained. In Regulatory Guide 1.111 Position C.2.b, $M$ is determined using the ratio of the effluent vertical velocity $W_{0}$ to the wind speed $\bar{U}$ according to:

$$
M= \begin{cases}1 & W_{0} / \bar{U}<1.0 \\ 2.58-1.58\left(W_{0} / \bar{U}\right) & 1.0 \leq W_{0} / \bar{U}<1.5 \\ 0.3-0.06\left(W_{0} / \bar{U}\right) & 1.5 \leq W_{0} / \bar{U}<5 \\ 0 & W_{0} / \bar{U} \geq 5 .\end{cases}
$$

The normalized concentrations are computed using sector average models. The sector average model for ground-level concentrations from elevated releases is

$$
\left(\frac{X \bar{U}}{\bar{Q}^{\top}}\right)_{\text {elev }}=\frac{2.032}{x \frac{\sigma_{z}(x)}{z} \exp }\left\{-\frac{h_{e}{ }^{2}}{2 \sigma_{z}^{2}(x)}\right\}
$$

Where $X$ is the ground level concentration, $Q^{\prime}$ is the release rate, $x$ is the downwind distance, $\sigma_{z}(x)$ is the vertical diffusion coefficient, and $h_{e}$ is the effective release height. The constant 2.032 includes a factor of $(2 / \pi)^{1 / 2}$ and the factor to convert $22.5^{\circ}$ to radians. For releases of material entrained in building wakes, the sector average diffusion model is 


$$
\left(\frac{x \overline{\bar{U}}}{Q^{\top}}\right)_{\text {entr }}=\frac{2.032}{x_{z}(x)}
$$

where $\beta_{Z}(x)$ is an augmented vertical diffusion coefficient. It is evaluated as the smaller of

$$
\beta_{z}(x)= \begin{cases}\left(\sigma_{z}{ }^{2}(x)+\frac{c A}{\pi}\right)^{1 / 2} \\ \text { or } \\ \sqrt{3} & \sigma_{z}(x)\end{cases}
$$

where $A$ is an area representative of the upwind face of the building and $c$ is an empirical constant usually given the value 0.5. The square of the building height may be used as the representative area. More detailed discussions of the sector average diffusion models may be found in Meteorology and Atomic Energy--1968 (Slade 1968) and in Regulatory Guide 1.111.

Figures 3 and 4 show the decrease in normalized concentrations for fully elevated and entrained plumes, and for plumes where $M$ has the values of 0.5 and 0.1 . For purposes of illustration, the diffusion coefficients corresponding to Pasquill-Gifford Stability classes $F$ and $C$ have been assumed for Figures 3 and 4 , respectively. The effective release height for the elevated plume was assumed to be $60 \mathrm{~m}$, and the effective building area for the wake model was assumed to be $3600 \mathrm{~m}^{2}$.

These two figures clearly illustrate that the significance of the Split-H concept is greatest close to the source and during stable atmospheric conditions. As the atmosphere becomes less stable and/or the distance from the source increases, the effect of averaging concentrations from elevated and ground level plumes decreases. For $F$ stability the maximum range of concentrations using the Split-H model covers less than a factor of 2 at $10 \mathrm{~km}$. During the neutral to slightly unstable conditions represented by $\mathrm{Class} C$, the range is reduced to less than a factor of 2 within $0.8 \mathrm{~km}$ of the source. 


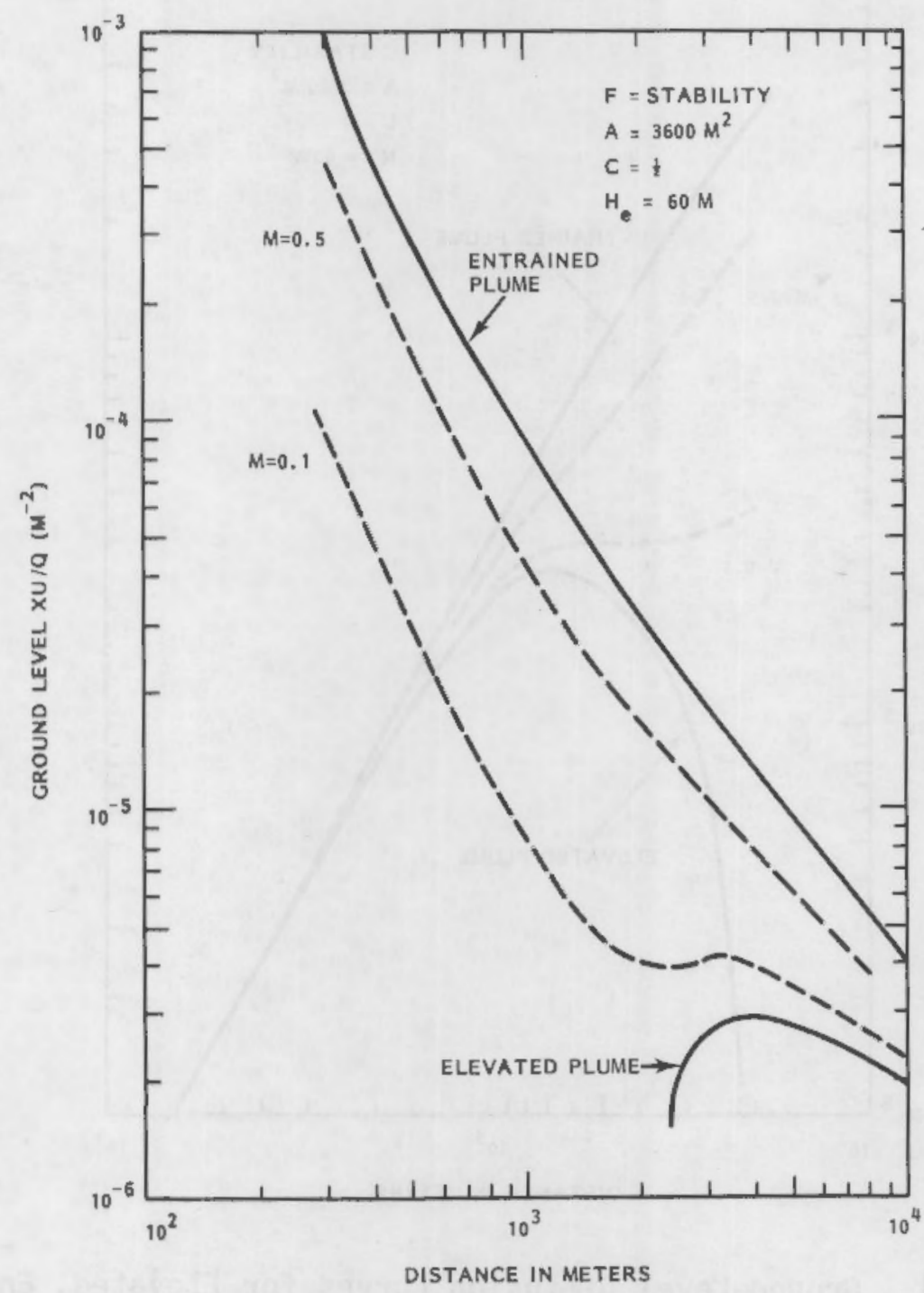

FIGURE 3. Ground-Level Diffusion Curves for Elevated, Entrained and Mixed Mode Plumes for F Stability 


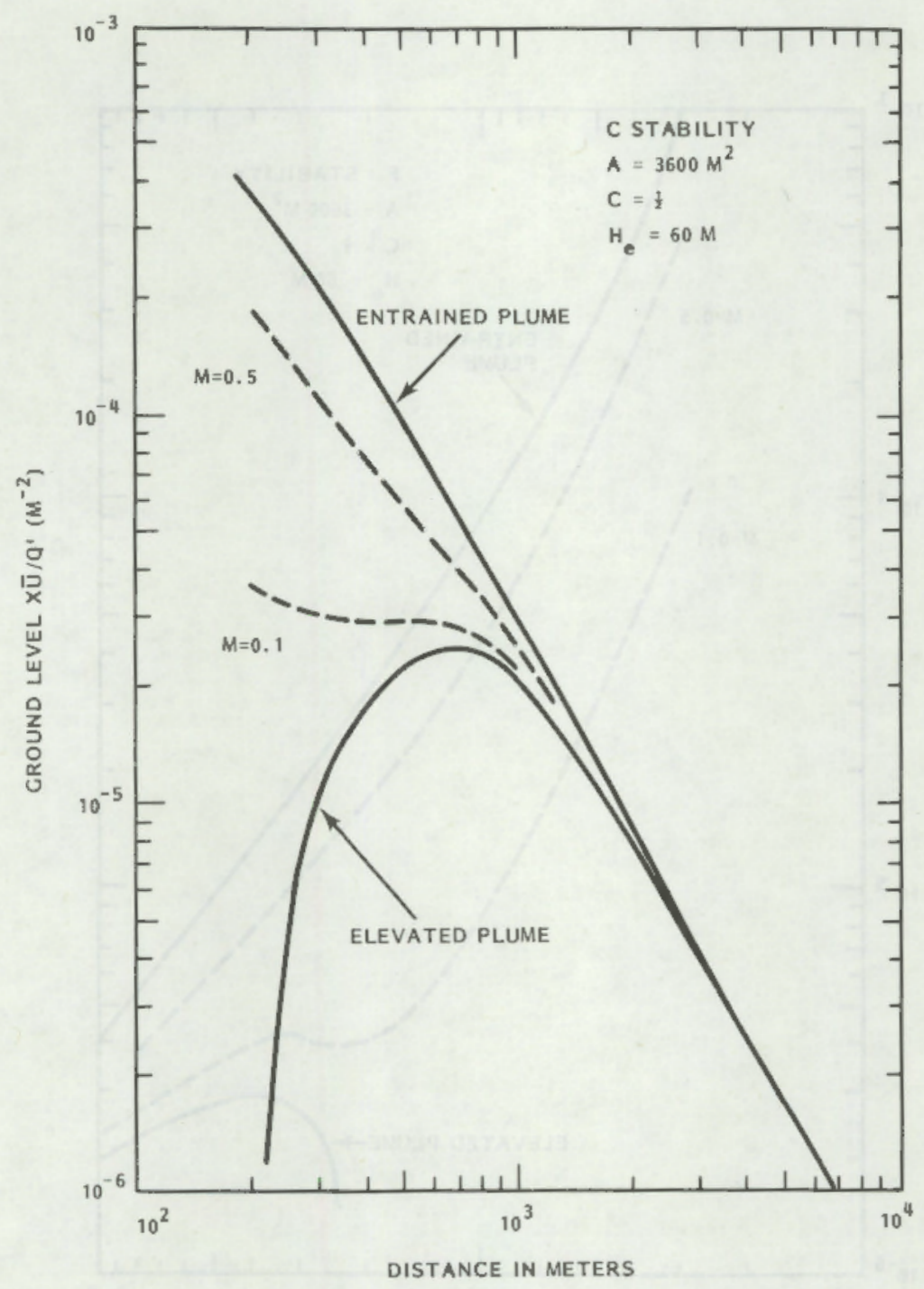

FIGURE 4. Ground-Level Diffusion Curves for Elevated, Entrained and Mixed Mode Plumes for C Stability 
Real time emergency response applications of diffusion models may be considred in three time frames. When an abnormal condition is discovered, an initial response is required within 15 minutes of the discovery. Over a period of an hour or two following the discovery, the response capability will increase as emergency response facilities are activated, and improved estimates of the potential consequences of the abnormal conditions will be made. This is the intermediate response phase. If the abnormal condition persists, it may be necessary to consider controlled releases to maintain stability of the facility.

Classification of the emergency in the initial response phase is based upon reactor condition and may be based upon assumed meteorological conditions. The refinements in estimated concentrations that might be possible using a Split-H model are not appropriate at this time, because the concept is more applicable in estimating long-term average concentrations than it is to estimating concentrations from short-term releases.

During the intermediate response phase of an emergency, all available meteorological data and diffusion models can be used to estimate the consequences of any actual or potential releases. Thus, there is an opportunity to ut ilize a Split-H model, if one is available. The benefits to be realized from a Split-H model in this application would be highiy site and situation dependent.

In the intermediate response phase of an emergency, the use of Split-H models is not related to initial decisions or actions. Rather, it is related to refinements in the decisions and actions as the emergency unfolds. A properly tested Split-H model might be used to evaluate the level of conservatism of initial diffusion estimates. On the basis of an analysis of this type, it might be realistic to modify the emergency classification, particularly for Class 1 through $\mathrm{Cl}$ ass 8 accidents. Another potentially useful application of a Split-H model in the intermediate response phase, is as a tool to be used in deploying monitoring teams. In this application, the model would estimate the plume, elevated or entrained, that contained the largest fraction of the released material. Estimation of concentrations would be a secondary use of the model.

\section{APPLICATION TO ROUTINE RELEASES}

In considering the application of the Split-H concept to the evaluation of the consequences of routine releases from nuclear facilities, it is important to note that the major contributions to the fence line and population exposures may come from releases during low wind speed, stable atmospheric conditions. These are precisely the conditions under which a Split-H model would give the greatest reduction in concentrations. At a hypothetical fence line distance of $1.0 \mathrm{~km}$, if a long-term average value of 0.5 is assumed for $M$, the 
reduction in normalized exposure would be a factor of 2. However, $F$ stability tends to be associated with low winds, 0.5 may be too large for an average $M$.

Johnson et al. (1975) used the meteorological data from one year at Millstone to evaluate the effect of the Split-H model that they proposed on the annual average normalized concentration. The reduction in concentration was about a factor of 7. When the individual directions were analyzed, the reduction factor at $500 \mathrm{~m}$ ranged between 5 and 20 because of the local correlations between wind direction, wind speed and stability.

In summary, Split-H models modify concentration estimates most significantly close to the release point and during stable atmospheric conditions. Their utility is likely to be greatest in evaluation of the consequences of routine atmospheric releases and during the later phases of an emergency.

\section{GENERALITY OF THE SPLIT-H CONCEPT}

The Split-H concept has its basis in the observed behavior of plumes from vents and short stacks; the fundamental validity of the concept is well established. However, during routine use of the concept in the licensing and regulation of nuclear facilities, it is necessary to demonstrate that the conditions under which the concept can be applied are identifiable.

One method of establishing the required generality might be to develop a $\mathrm{Split}-\mathrm{H}$ model, starting from fundamental physical relationships such as the equations of motion and conservation of mass. However, as pointed out earlier, this involves modeling vertical plume rise and building wakes; neither is tractable mathematically without extensive simplification and assumptions.

A second approach is to attempt to establish generality through physical modeling in wind tunnels and flumes. This approach has yet to yield conclusive results. Reproducible results are obtained in modeling air flow and diffusion in simple cases in wind tunnels and flumes, but there is an insufficient number of corresponding full scale measurements to confirm that flow and diffusion in the real atmosphere behave as they do in the physical models. In the case of flow and diffusion around building complexes, comparisons between physical modeling and full scale studies get mixed results. In some cases at least qualitative agreement exists between results of the two types of studies. In other cases the results are disappointingly disparate.

Hosker (1981) discusses the results of physical modeling studies in detail and compares them with results from field studies when possible. It appears that ensemble averaging of the results from a series of field tests improves the comparison with results of physical modeling. This finding could have 
been anticipated because models are best suited to the description of mean behavior. The many factors not incorporated in models lead to the differences between individual field experiments.

A third approach to establishing the generality of the Split-H concept is to develop a model and test the model at a wide variety of nuclear facilities. The distribution of effluent between elevated and entrained plumes, as suggested by Rodliffe and Fraser (1971) and Johnson et al. (1975) is one part of such a mode1. This part is represented by Equation (1). It is relatively easy to accept the generality of this representation.

A second and more important part of the model consists ot the set of criteria used to determine the distribution. The definitions of $M$ under various conditions shown in Equation (2) are representative of this portion of the model. Rodliffe and Fraser (1971), Philadelphia Electric (1974) and Johnson et al. (1975) give sets of empirically derived criteria for the facility where the experiments were conducted. None of the criteria are represented as being general. It is not surprising, then, that Thuillier and Mancuso (1980) found that the Millstone criteria were not appropriate for the Duane Arnold Energy Center. Hosker (1981) briefly discusses the likelihood of developing generally applicable models for treating diffusion in the vicinity of building complexes. His conclusions are rather pessimistic. However, he may have been concerned with a higher degree of detail than might be necessary for this application. It may be necessary to trade a degree of conservatism in order to achieve an acceptable level of generality. The next section discusses potential components of an upgraded Split-H model.

\section{AN UPGRADED SPLIT-H MODEL}

The discussion in this section outlines a Split-H model that is more general than the models offered by Johnson et al. (1975) and contained in Regulatory Guide 1.111, Position C.2.b. The model is for estimation of long-term average concentrations. The accuracy of the model, and therefore its acceptability, must be established by comparison of model results with actual data collected at nuclear facilities.

The model development is presented in two stages. In the initial stage, the full model is described in terms of variables such as plume height, plume radius and building wake dimensions. In the second stage, existing models of plume rise and spread and building wake dimensions are used to fill in the details of the Split-H model. These models incorporate the effects of many of the relevant atmospheric conditions and building dimensions. 


\section{MODEL COMPONENTS}

Figure 5 combines the essential features of Figures 1 and 2 to $i 11$ ustrate the physical problem being treated. The building is characterized by a height $\mathrm{H}_{b}$, a crosswind dimension $W_{b}$, and an along-wind dimension, $L_{b}$. With the wind blowing with a speed $U$ from left to right, the building generates a wake that is partially characterized by the upper boundaries $z_{t}$ of the highly turbulent layer and $z_{r}$ of the roof wake, respectively. Effluent is released from a vent or short stack at or slightly above the roof. The plume rises due to its own initial vertical momentum. As the plume rises it is bent over. The behavior of the plume downwind of the building depends on the relationship between the final plume height and the height of the wake boundaries.

The relationship between the plume and the building wake is shown in more detail in Figure 6 . To facilitate the mathematical development of the model, Cartesian coordinates have been included. The origin of the coordinate system is fixed to the upwind edge of the roof with the abscissa directed downwind. The release occurs through a vent with radius $R_{v}$ at position $\left(x_{v}\right.$, $\left.\mathrm{H}_{\mathrm{y}}\right)$.

\section{UPGRADED SPLIT-H MODEL EQUATIONS}

The model consists of Equation (1) and a new set of criteria for determining the distribution of material between the elevated and entrained plumes. Rather arbitrarily, the downwind edge of the building is chosen as the reference point for evaluation of the criteria used to determine $M$. At this location the plume has a height $H_{p}$ and a radius $R_{p} . H_{p}$ is the sum of $H_{y}$ and plume rise due to momentum, $H_{r}$. (The effect of plume buoyancy can be included, if appropriate.) Assuming that the plume is fully bent over by the time it reaches the reference point, the bottom of the plume $H^{\prime}$ is $H_{p}-R_{p}$, and $z_{t}$ and $z_{r}$ have the values $z_{1}$ and $z_{2}$, respectively. plume types are then:

$\begin{array}{ll}\text { Plume Type } & \text { Condition } \\ \text { Elevated } & H^{\prime}>z_{2} \\ \text { Mixed Mode } & z_{1}<H^{\prime}<z_{2} \\ \text { Entrained } & H^{\prime}<z_{1}\end{array}$

For short duration releases (of the order of a few hours or less) the corresponding $M$ definitions are suggested: 


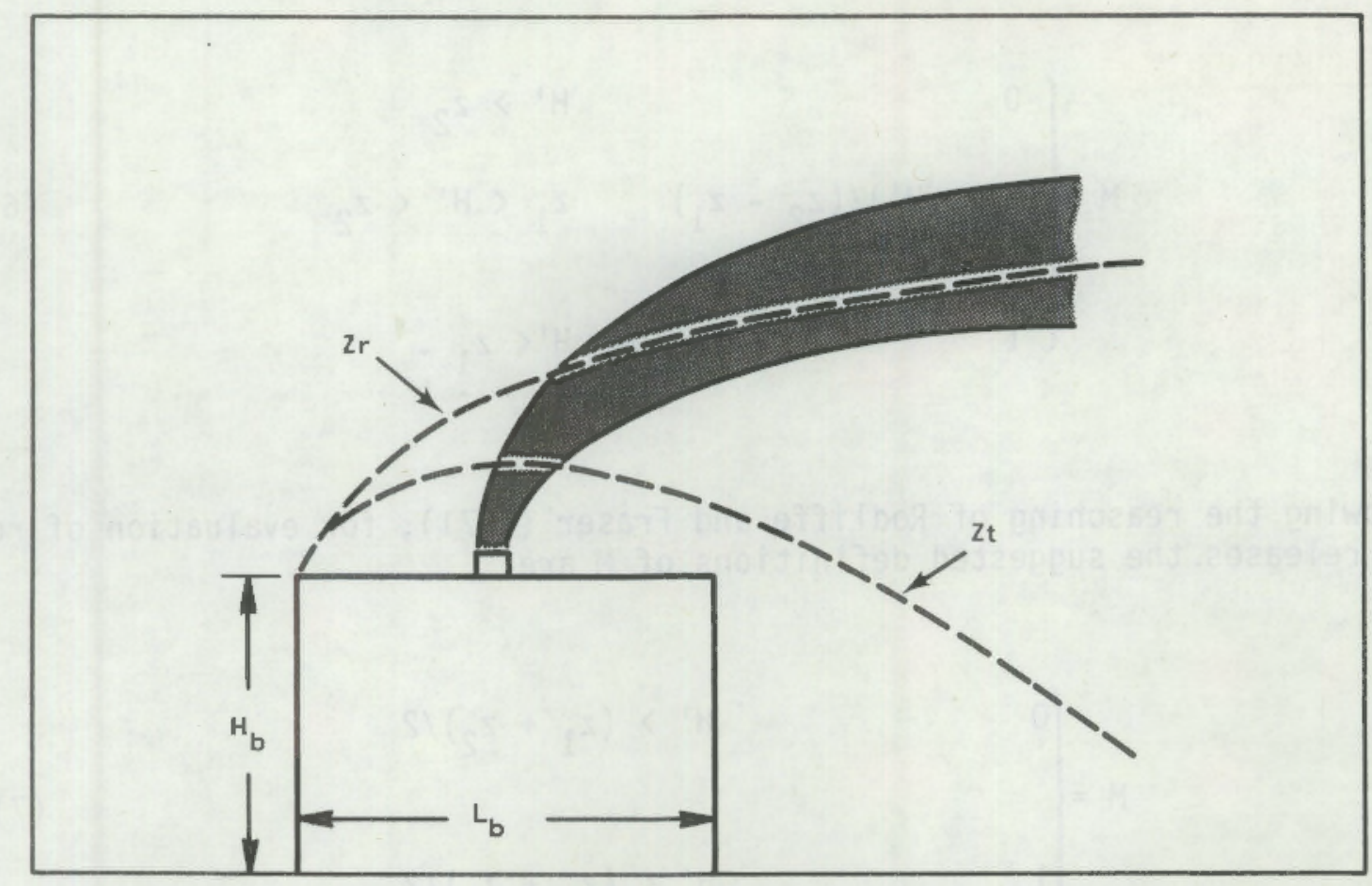

FIGURE 5. Vertical Jet in the Presence of a Building Wake

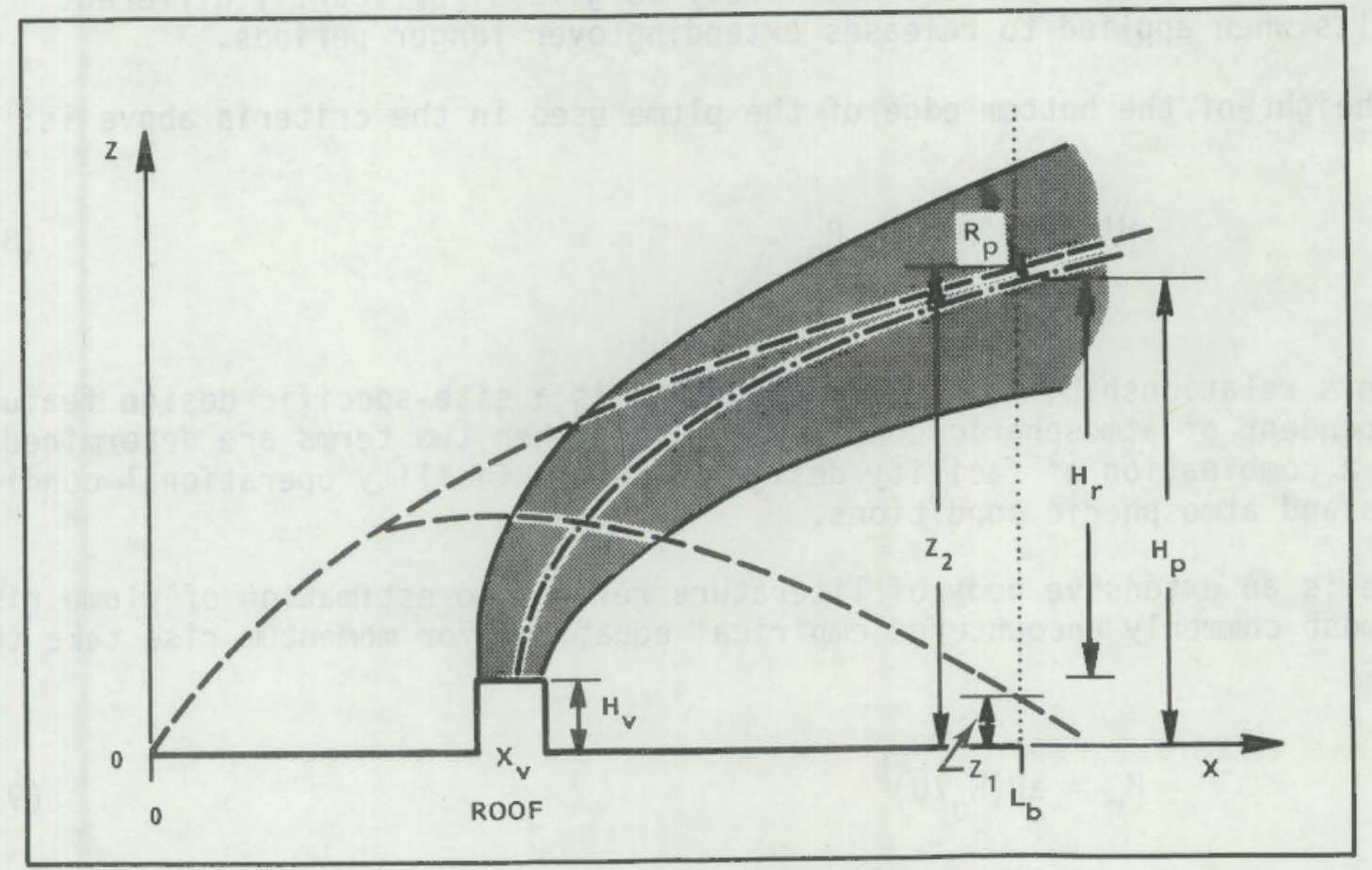

FIGURE 6. Characteristic Dimensions Used in the Upgraded Split-H Model 


$$
M= \begin{cases}0 & H^{\prime}>z_{2} \\ \left(z_{2}-H^{\prime}\right) /\left(z_{2}-z_{1}\right) & z_{1}<H^{\prime}<z_{2} \\ 1 & H^{\prime}<z_{1} .\end{cases}
$$

Following the reasoning of Rodliffe and Fraser (1971), for evaluation of routine releases the suggested definitions of $M$ are:

$$
M= \begin{cases}0 & H^{\prime}>\left(z_{1}+z_{2}\right) / 2 \\ 1 & H^{\prime}<\left(z_{1}+z_{2}\right) / 2 .\end{cases}
$$

The two sets of criteria are not likely to give significantly different results when applied to releases extending over longer periods.

The height of the bottom edge of the plume used in the criteria above is:

$$
H^{\prime}=H_{v}+H_{r}-R_{p}
$$

In this relationship, $H_{v}$ shown in Figure 6 is a site-specific design feature independent of atmospheric conditions. The other two terms are determined from a combination of facility design features, facility operational conditions and atmospheric conditions.

There is an extensive body of literature related to estimation of plume rise. The most commonly encountered empirical equations for momentum rise take the form:

$$
H_{r}=a D\left(w_{0} / \bar{U}\right)^{b}
$$


where the parameters $a$ and $b$ take on relatively wide ranges of values. Considering only the values recommended by Smith (1968), Briggs (1969), Csanady (1973) and Hanzevack (1982), and the values cited by Briggs (1975), the values of a range from 1 to 4 . The same sources give values of $b$ ranging from 0.78 to 1.4 . The consensus of the more recent work is that a should be about 3 and that b should be about 1, although Hanzevack (1982) recommends using $b=1.4$. In this formulation, plume rise is independent of atmospheric stability.

When atmospheric stability is an important factor in limiting momentum rise, the plume rise equations developed from similarity theory that are recommended by Briggs (1969) can be used in place of Equation (9). For calm, stable periods, plume rise is given by

$$
H_{r}=2.8\left(w_{0} D\right)^{\frac{1}{2}}\left(\frac{g}{T} \frac{\partial \theta}{\partial z}\right)^{-\frac{1}{4}}
$$

where $g$ is the gravitational acceleration, $T$ is the ambient temperature and $\partial \theta / \partial z$ is the potential temperature gradient. During stable, windy periods, plume rise is given by

$$
H_{r}=0.94\left(\frac{W_{0}^{2} D^{2}}{D}\right)^{\frac{1}{3}}\left(\frac{g}{T} \frac{\partial \theta}{\partial z}\right)^{-\frac{1}{6}} .
$$

In either case, a theoretical limit to the equilibrium rise of vertical jets is

$$
H_{r}=1.7\left(W_{0} D\right)^{\frac{1}{2}}\left(\frac{g}{T} \frac{\partial \theta}{\partial z}\right)^{-\frac{1}{4}} .
$$

according to Hanna, Briggs and Hosker (1982). This limit is apparently supported by laboratory and field experiments. For unstable atmospheric conditions, use of the neutral stability equation given in Equation (9) should be conservative.

Briggs (1975) contains an extensive discussion of the assumptions used by numerical modelers of plume rise to close their sets of equations. Most frequently these assumptions involve the rate of lateral growth of the plume due to entrainment. For vertical jets near the point of release, the consensus 
is that the growth of the plume is initially due to turbulence within and generated by the plume. As a result, a well-established closure assumption is that the radius of the plume increases in direct proportion to the plume rise. The accepted value (Hanna, Briggs and Hosker 1982) of the constant of proportionality is 0.16 . On this basis, the plume radius to be used in computing $H^{\prime}$ is:

$$
R_{p}=\frac{0}{2}+0.16 H_{r} \text {. }
$$

Equation (13) is strictly applicable only for the vertical portion of the plume, but it is also a good approximation for the bent over plume near the release point. Combining Equations (8), (9) and (13), and substituting for a and $b$ gives the following equation for momentum plume rise under neutral atmospheric conditions:

$$
H^{\prime}=H_{v}+2.5 D\left(\frac{W_{0}}{U}\right)-\frac{D}{2} \cdot
$$

The corresponding expressions for stable conditions are only slightly more complex.

The remaining task in the development of a general Split- $H$ model is to estimate the two heights $z_{1}$ and $z_{2}$. The pertinent information in the literature is summarized by Hosker (1981) and Hanna, Briggs and Hosker (1982). Generally it results from wind tunnel modeling studies and is unsupported by adequate full scale studies. As a result, the following discussion should be considered to be tentative. Certainly the use of the following building wake model represents an extrapolation well beyond experimental limits.

Wilson (1979a and b) originated the general wake description shown in Figure 2. In addition, he developed a set of equations for the three wake boundaries shown. These equations are expressed in terms of a scale dimension for the building. If $P$ is the smaller of the building height or width and $Q$ is the larger, the scale dimension $L_{s}$ is:

$$
L_{s}=P^{\frac{2}{3}} Q^{\frac{1}{3}}
$$

The maximum height of the recirculation cavity on the roof is $0.22 \mathrm{~L}_{\mathrm{s}}$. It occurs at a distance of $\mathrm{L}_{\mathrm{s}} / 2$ from the upwind edge of the roof. If $\mathrm{L}_{b}$ is greater than $0.9 \mathrm{~L}_{s}$, the recirculation cavity boundary reattaches to the roof. Otherwise, the cavity extends to the ground in the lee of the building. 
Between the upwind edge of the roof and $\mathrm{L}_{s} / 2$, the three wake boundaries are essentially coincident. In this region the growth of the boundaries is described by:

$$
z_{r}=0.28 L_{s}\left(x / L_{s}\right)^{\frac{1}{3}} .
$$

This equation also describes the growth of the top of the roof wake layer for $x$ greater than $L_{S} / 2$. Downwind of $x=L_{S} / 2$, the top of the high turbulence layer is given approximately by:

$$
z_{t}=0.27 L_{s}-0.1 x \text {. }
$$

In the case of a long building, $z_{t}$ should not be allowed to become less than zero.

Equations (15) through (17) were developed for flow across a rectangular building with a face perpendicular to the wind. Wind tunnel tests of Koga and Way (1979) provide a strong indication that building wake structure is rather sensitive to building orientation with respect to the wind. Hosker (1981) cautions against extrapolation of results from one building shape to another. Therefore, the equations should be used with a good deal of reservation.

As field data become available and are analyzed, a different definition of the building scale dimension may give better results than the one given by Wilson. Sagendorf et a1. (1980) achieved good results in reduction of the scatter of building wake diffusion data when the square root of the minimum cross-sectional area of the building was used as a scale dimension. An attempt to scale with the building height did not prove successful. For those cases in which the wind approaches a building at an oblique angle, the square root of frontal area of the building, projected on a plane perpendicular to the wind vector may be an appropriate scaling dimension.

The general Split-H model is now complete, at least in preliminary form. The greatest degree of generality in the model is found in the basic model framework. The model details related to plume rise are based on a combination of theoretical results, wind tunnel studies and field observations. To complete the model development, a building wake description based on wind tunnel studies has been added. That description is the least general portion of the model.

In the remainder of the report, the Upgraded Split-H Model specifically refers to the following: The criteria for determining the release mode are given in Equation (6). The height of the bottom edge of the plume is given by Equation (8). Equation (9), with $a=3$ and $b=1$, is used for plume rise 
in neutral conditions. During stable conditions plume rise is given by Equations (10) and (11) subject to the constraints that it must not be greater than plume rise for neutral conditions with the same wind speed or the maximum $\mathrm{plume}$ rise given by Equation (12). The ambient temperature of $15^{\circ} \mathrm{C}$ is assumed in the stable plume rise computations. In computing the plume radius, a constant value of $30 \mathrm{~m}$ is used for $\mathrm{H}_{r} ; 30 \mathrm{~m}$ corresponds to the distance from the assumed release point to the downwind edge of the building. The extent of the building wake is determined from Equations (15) through (17). The Rodliffe and Fraser model uses the criteria in Equation (7) in place of those in Equation (6). The remainder of the equations in the Rodliff and Fraser model are the same as those in the upgraded model.

\section{COMPARISON OF SPLIT-H MODELS}

The basic Split-H concept involves consideration of plume rise and building wakes. The upgraded model developed in the last section combines existing plume rise and building wake models. It treats a number of structural features of buildings explicitly. These features include the overall building dimensions, the height of the release point above the roof of the building and the inside dimension of the vent. Effects of wind direction, although important, are not treated explicitly by the model.

Once the basic dimensions of a facility are established, the distribution of the effluent between an elevated plume and a plume entrained in the wake of the building is determined by the ratio of the effluent vertical velocity to the wind speed. This is clearly evident from Equations $(6),(7),(14),(16)$ and (17). Under these conditions, a set of critical ratios of $W_{0} / U$ can be established to replace the criteria in Equations (6) and (7). The critical ratios are site specific because they are determined from building dimensions. They are also functions of atmospheric stability.

Position C.2.b of Regulatory Guide 1.111 uses the $W_{0} / U$ ratio as the sole factor in distribution of vent effluents between elevated and entrained plumes in estimating annual average ground-level concentrations. Generic values are provided for critical ratios. The essential difference between the two Split-H models is not in the importance of the ratio between effux velocity and wind speed, rather it is in the treatment of other factors. The upgraded model explicitly treats several of these factors that are not treated by the Regulatory Guide model.

\section{COMPARISON SCENARIO}

To explore the significance of the differences between the upgraded and Regulatory Guide 1.111 Split-H models, estimates of the annual average concentration were made for 20 wind direction sectors for 18 different nuclear power plant sites. A common reactor building complex geometry was assumed. It consisted of a cubical building $60 \mathrm{~m}$ on a side and a release point at the center of the roof. The wind was assumed to be perpendicular to a building face for each sector. The terrain in the vicinity of the reactor was assumed to be flat. 
The reactor building variables for the comparisons were vent diameter and effluent vertical velocity. Diameters between 1 and $4 \mathrm{~m}$ were combined with vertical velocities of 5,10 and $20 \mathrm{~m} / \mathrm{s}$ to give effluent flows ranging from 15.7 to $125.7 \mathrm{~m}^{3} / \mathrm{s}$.

Annual average, normalized concentrations were estimated for each combination of vent diameters and vertical velocities for the 20 sectors at 18 different nuclear power plant sites using 4 models. The models used were: 1) the ground-level, wake-entrained plume model, 2) the upgraded Split-H model with the Equation (6) entrainment criteria, 3) the upgraded Split-H model with the Equation (7) entrainment criteria, and 4) the Regulatory Guide 1.111 Split-H model. The equations used for the elevated and ground-level, wake-entrained plumes were derived from Equations (3) and (4) for use with climatological data, i.e.

$$
\left(x / Q^{\prime}\right)_{e l e v}=2.032 \sum_{i} \sum_{j} \frac{f_{i j}}{x \bar{U}_{i j} \sigma_{z j}(x)} \exp \left(-\frac{h_{e}{ }^{2}}{2 \sigma_{z j}{ }^{2}(x)}\right)
$$

and

$$
\left(x / Q^{\prime}\right)_{\text {entr }}=2.032 \sum_{i} \sum_{j} \frac{f_{i j}}{x \bar{U}_{i \beta}{ }_{z j}(x)}
$$

where $f_{i j}$ is the joint frequency of occurrence of wind speed class $i$, represented by $\bar{U}_{j}$, and stability class $j$, represented by $\sigma_{z j}(x)$ and $\beta_{z j}(x)$.

The joint frequency of occurrence $f_{i j}$ is given in climatological tables submitted to the NRC by applicants and licensees. However, for the present purpose, the usual wind speed classes in the submissions to the NRC are too coarse. In place of the tabled data, $f_{i j}$ was computed from:

$$
\left.f_{i j}=P \text { (speed class } i \mid \bar{U}_{j}\right) F \text { (stability class } j \text { ) }
$$

where $P$ (speed class $i \mid \bar{U}_{j}$ ) is the conditional probability of occurrence of speed class $i$ given the mean speed $\bar{U}_{j}$ for stability class $j$, and $F$ (stability class $j$ ) is the frequency of occurrence of stability class $j$. The frequency of occurrence and mean wind speed for each stability class were obtained from the tabled data. 
To estimate $P$ (speed class $i \mid \bar{U}_{j}$ ), wind speeds were assumed to have a Rayleigh distribution (see Papoulis (1965) for a discussion of the Rayleigh distribution). With this assumption, the probability of the wind speed being in the range between two limits, say $a$ and $b$, is a function only of the mean wind speed. This probability is given by:

$$
P(a<b \mid \bar{U})=\exp \left(-\frac{\pi a^{2}}{4 \bar{U}^{2}}\right)-\exp \left(-\frac{\pi b^{2}}{4 \bar{U}^{2}}\right) \cdot
$$

The wind speed $\mathrm{classes}$ used in the comparison computations were $0.5 \mathrm{~m} / \mathrm{s}$ in width and ranged from 0 to $20 \mathrm{~m} / \mathrm{s}$. The wind speeds above $20 \mathrm{~m} / \mathrm{s}$ were treated as a single class with a mean speed of $20.5 \mathrm{~m} / \mathrm{s}$. Use of the Rayleigh distribution for wind speeds is relatively common.

Table 1 lists the locations and wind direction sectors that provided the meteorological data set used in the comparison computations. It also gives the mean speed for and frequency of occurrence of each stability class for the sector. The speeds are in meters per second, and the frequencies of occurrence are in percent. № adjustments have been made to the wind speeds to attempt to account for differences between the measurement height and the effective release heights used in the computations. The last column in the table gives the weighted average wind speed for the sector.

TABLE 1. Meteorological Oata Set Used in Model Comparisons. Wind speeds are in meters/second and frequencies are in percent.

Wind

$\frac{\text { Site }}{\text { Big Rock }}$

Brown's

Ferry

Cooper

Dresden
Direction

W

SE $\quad$ spd

freq

N spd

freq

E $\quad$ spd

freq
Stability Class

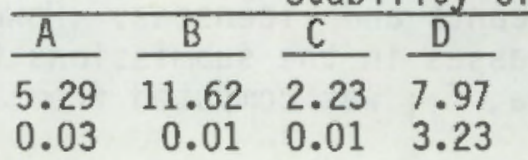

$\frac{E}{6.27}$

$\begin{array}{ll}\frac{F}{5.87} & \frac{G}{4.62} \\ 0.67 & 0.16\end{array}$

$\begin{array}{llll}2.14 & 1.82 & 1.69 & 2.00\end{array}$

$0.56 \quad 3.90$

1.93

5.96

$1.49 \quad 1.13$

2.09

1.00

7.48

7.18

6.00

1.25

4.40

1.03

2.74

0.73

0.98

3.81

5.29

0.57

4.79

0.18

$4.48 \quad 4.69$

$0.18 \quad 1.79$

3.61

2.49
Weighted Average Speed

6.77

1.84

6.74

4.05 
TABLE 1. (cont).

\begin{tabular}{|c|c|c|c|c|c|c|c|c|c|c|}
\hline \multirow[b]{2}{*}{$\frac{\text { Site }}{\text { Ginna }}$} & \multirow{2}{*}{$\begin{array}{c}\text { Wind } \\
\text { Direction } \\
\text { SW }\end{array}$} & \multirow[b]{2}{*}{$\begin{array}{l}\text { spd } \\
\text { freq }\end{array}$} & \multicolumn{7}{|c|}{ Stability Class } & \multirow{2}{*}{$\begin{array}{l}\text { Weighted } \\
\text { Average } \\
\text { Speed } \\
2.79\end{array}$} \\
\hline & & & $\begin{array}{l}\frac{A}{3.20} \\
0.52\end{array}$ & $\begin{array}{l}\text { B } \\
3.73 \\
0.13\end{array}$ & $\begin{array}{l}\frac{C}{3.71} \\
0.19\end{array}$ & $\begin{array}{l}\frac{D}{3.23} \\
1.73\end{array}$ & $\begin{array}{l}\frac{E}{2.88} \\
5.10\end{array}$ & $\begin{array}{l}\frac{F}{2.31} \\
1.82\end{array}$ & $\begin{array}{l}\frac{G}{2.09} \\
1.23\end{array}$ & \\
\hline Hatch & SW & $\begin{array}{l}\text { spd } \\
\text { freq }\end{array}$ & $\begin{array}{l}3.34 \\
1.72\end{array}$ & $\begin{array}{l}3.29 \\
0.41\end{array}$ & $\begin{array}{l}3.40 \\
0.33\end{array}$ & $\begin{array}{l}3.08 \\
2.34\end{array}$ & $\begin{array}{l}2.36 \\
2.42\end{array}$ & $\begin{array}{l}2.05 \\
0.78\end{array}$ & $\begin{array}{l}1.92 \\
0.89\end{array}$ & 2.75 \\
\hline $\begin{array}{l}\text { Humboldt } \\
\text { Bay }\end{array}$ & N & $\begin{array}{l}\text { spd } \\
\text { freq }\end{array}$ & & & & $\begin{array}{l}8.08 \\
0.76\end{array}$ & $\begin{array}{r}5.86 \\
17.31\end{array}$ & $\begin{array}{l}2.81 \\
0.69\end{array}$ & $\begin{array}{l}2.34 \\
0.09\end{array}$ & 5.82 \\
\hline $\begin{array}{l}\text { Nine Mile } \\
\text { Point }\end{array}$ & $\mathrm{s}$ & $\begin{array}{l}\text { spd } \\
\text { freq }\end{array}$ & $\begin{array}{l}5.48 \\
0.20\end{array}$ & & $\begin{array}{l}2.82 \\
2.40\end{array}$ & $\begin{array}{l}5.12 \\
3.30\end{array}$ & & $\begin{array}{l}3.07 \\
5.30\end{array}$ & & 3.66 \\
\hline $\begin{array}{l}\text { Oyster } \\
\text { Creek }\end{array}$ & WNW & $\begin{array}{l}\text { spd } \\
\text { freq }\end{array}$ & $\begin{array}{l}4.19 \\
0.92\end{array}$ & $\begin{array}{l}4.49 \\
0.32\end{array}$ & $\begin{array}{l}4.70 \\
0.51\end{array}$ & $\begin{array}{l}4.50 \\
2.24\end{array}$ & $\begin{array}{l}2.79 \\
4.07\end{array}$ & $\begin{array}{l}2.05 \\
1.39\end{array}$ & $\begin{array}{l}1.65 \\
1.67\end{array}$ & 3.12 \\
\hline $\begin{array}{l}\text { Point } \\
\text { Beach }\end{array}$ & SSW & $\begin{array}{l}\text { spd } \\
\text { freq }\end{array}$ & $\begin{array}{l}3.06 \\
0.06\end{array}$ & $\begin{array}{l}1.99 \\
0.09\end{array}$ & $\begin{array}{l}4.31 \\
0.36\end{array}$ & $\begin{array}{l}6.39 \\
4.66\end{array}$ & $\begin{array}{l}5.94 \\
5.56\end{array}$ & $\begin{array}{l}4.29 \\
1.13\end{array}$ & $\begin{array}{l}3.57 \\
0.73\end{array}$ & 5.73 \\
\hline $\begin{array}{l}\text { Quad } \\
\text { Cities }\end{array}$ & s & $\begin{array}{l}\text { spd } \\
\text { freq }\end{array}$ & $\begin{array}{l}4.17 \\
2.12\end{array}$ & $\begin{array}{l}4.38 \\
0.31\end{array}$ & $\begin{array}{l}4.16 \\
0.35\end{array}$ & $\begin{array}{l}4.34 \\
2.20\end{array}$ & $\begin{array}{l}4.23 \\
5.64\end{array}$ & $\begin{array}{l}3.28 \\
1.11\end{array}$ & $\begin{array}{l}1.92 \\
0.21\end{array}$ & 4.11 \\
\hline San Onofre & WNW & $\begin{array}{l}\text { spd } \\
\text { freq }\end{array}$ & $\begin{array}{l}3.93 \\
6.76\end{array}$ & $\begin{array}{l}3.22 \\
0.40\end{array}$ & $\begin{array}{l}3.22 \\
0.50\end{array}$ & $\begin{array}{l}3.90 \\
1.67\end{array}$ & $\begin{array}{l}3.16 \\
1.01\end{array}$ & $\begin{array}{l}2.51 \\
0.28\end{array}$ & $\begin{array}{l}1.95 \\
0.27\end{array}$ & 3.65 \\
\hline San Onofre & NE & $\begin{array}{l}\text { spd } \\
\text { freq }\end{array}$ & $\begin{array}{l}3.08 \\
0.09\end{array}$ & $\begin{array}{l}2.34 \\
0.08\end{array}$ & $\begin{array}{l}2.55 \\
0.11\end{array}$ & $\begin{array}{l}2.64 \\
0.87\end{array}$ & $\begin{array}{l}2.75 \\
1.71\end{array}$ & $\begin{array}{l}2.79 \\
2.37\end{array}$ & $\begin{array}{l}3.99 \\
8.18\end{array}$ & 3.51 \\
\hline Shoreham & N & $\begin{array}{l}\text { spd } \\
\text { freq }\end{array}$ & $\begin{array}{l}3.94 \\
1.34\end{array}$ & $\begin{array}{l}4.16 \\
0.40\end{array}$ & $\begin{array}{l}3.87 \\
0.26\end{array}$ & $\begin{array}{l}5.68 \\
1.61\end{array}$ & $\begin{array}{l}5.41 \\
1.59\end{array}$ & $\begin{array}{l}3.89 \\
0.33\end{array}$ & $\begin{array}{l}1.90 \\
0.10\end{array}$ & 5.12 \\
\hline Shoreham & SSW & $\begin{array}{l}\text { spd } \\
\text { freq }\end{array}$ & $\begin{array}{l}6.21 \\
1.89\end{array}$ & $\begin{array}{l}5.68 \\
0.80\end{array}$ & $\begin{array}{l}5.86 \\
0.45\end{array}$ & $\begin{array}{l}6.09 \\
3.65\end{array}$ & $\begin{array}{l}5.59 \\
3.74\end{array}$ & $\begin{array}{l}5.18 \\
0.89\end{array}$ & $\begin{array}{l}4.61 \\
0.73\end{array}$ & 5.77 \\
\hline Surrey & SSW & $\begin{array}{l}\text { spd } \\
\text { freq }\end{array}$ & $\begin{array}{l}3.69 \\
0.68\end{array}$ & $\begin{array}{l}3.37 \\
0.19\end{array}$ & $\begin{array}{l}3.69 \\
0.22\end{array}$ & $\begin{array}{l}3.56 \\
2.30\end{array}$ & $\begin{array}{l}3.62 \\
5.61\end{array}$ & $\begin{array}{l}1.67 \\
1.35\end{array}$ & $\begin{array}{l}1.01 \\
1.87\end{array}$ & 2.99 \\
\hline $\begin{array}{l}\text { Three Mile } \\
\text { Island }\end{array}$ & NW & $\begin{array}{l}\text { spd } \\
\text { freq }\end{array}$ & $\begin{array}{l}3.58 \\
2.27\end{array}$ & $\begin{array}{l}4.70 \\
0.32\end{array}$ & $\begin{array}{l}4.59 \\
0.43\end{array}$ & $\begin{array}{l}5.80 \\
5.77\end{array}$ & $\begin{array}{l}3.72 \\
3.29\end{array}$ & $\begin{array}{l}1.50 \\
0.48\end{array}$ & $\begin{array}{l}1.15 \\
0.17\end{array}$ & 4.52 \\
\hline Trojan & $S$ & $\begin{array}{l}\text { spd } \\
\text { freq }\end{array}$ & $\begin{array}{l}3.17 \\
0.31\end{array}$ & $\begin{array}{l}4.03 \\
0.16\end{array}$ & $\begin{array}{l}3.90 \\
0.36\end{array}$ & $\begin{array}{l}4.24 \\
6.75\end{array}$ & $\begin{array}{r}3.85 \\
10.10\end{array}$ & $\begin{array}{l}2.12 \\
1.94\end{array}$ & $\begin{array}{l}1.67 \\
0.18\end{array}$ & 3.78 \\
\hline
\end{tabular}


TABLE 1. (cont).

\begin{tabular}{|c|c|c|c|c|c|c|c|c|c|c|}
\hline \multirow[b]{2}{*}{ Site } & \multirow{2}{*}{$\begin{array}{c}\text { Wind } \\
\text { Direction }\end{array}$} & & \multicolumn{7}{|c|}{ Stability $\mathrm{Cl}$ ass } & \multirow{2}{*}{$\begin{array}{l}\text { Weighted } \\
\text { Average } \\
\text { Speed }\end{array}$} \\
\hline & & & $\bar{A}$ & $\bar{B}$ & $c$ & $D$ & $\bar{E}$ & $F$ & $G$ & \\
\hline Watts Bar & SSW & $\begin{array}{l}\text { spd } \\
\text { freq }\end{array}$ & $\begin{array}{l}4.05 \\
0.70\end{array}$ & $\begin{array}{l}3.80 \\
1.06\end{array}$ & $\begin{array}{l}3.35 \\
0.66\end{array}$ & $\begin{array}{l}3.18 \\
5.25\end{array}$ & $\begin{array}{l}3.29 \\
6.38\end{array}$ & $\begin{array}{l}1.65 \\
0.91\end{array}$ & $\begin{array}{l}0.83 \\
0.39\end{array}$ & 3.16 \\
\hline Zion & SW & $\begin{array}{l}\text { spd } \\
\text { freq }\end{array}$ & $\begin{array}{l}5.54 \\
1.85\end{array}$ & $\begin{array}{l}4.52 \\
0.23\end{array}$ & $\begin{array}{l}4.95 \\
0.35\end{array}$ & $\begin{array}{l}4.79 \\
1.64\end{array}$ & $\begin{array}{l}4.26 \\
3.44\end{array}$ & $\begin{array}{l}3.07 \\
1.40\end{array}$ & $\begin{array}{l}1.73 \\
0.72\end{array}$ & 4.26 \\
\hline
\end{tabular}

COMPARISONS BETWEEN THE UPGRADED AND REGULATORY GUIDE MODELS

The essential difference between the upgraded and Regulatory Guide 1.111

Split-H models is in the set of criteria used to determine whether a plume is elevated or not. In the Regulatory Guide model, the criteria are based only on the ratio between the effluent vertical velocity and wind speed. Figure 7

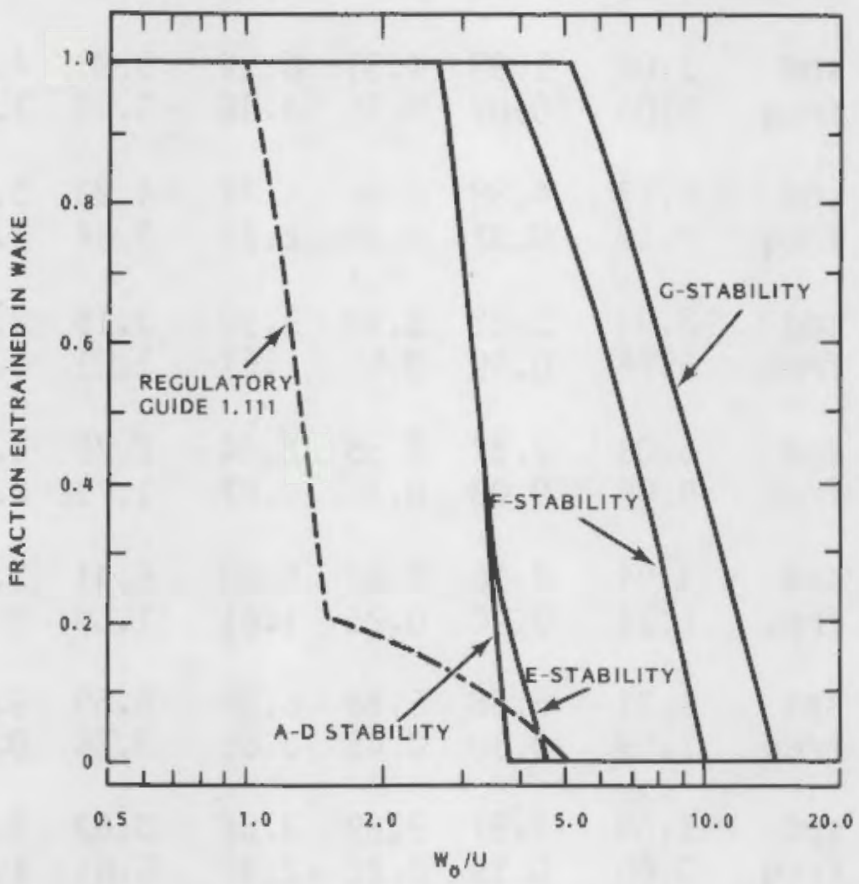

FIGURE 7. Comparison of Wake Entrainment Fractions for Upgraded and Regulatory Guide 1.111 Split-H Models 
shows the variation of the fraction of the plume entrained in the building wake for both models for the specific case of cubical reactor with a 2-m diameter vent and a $31.4 \mathrm{~m}^{3}$ flow. In the figure, since the vertical velocity is constant, the wind speed increases from right to left. The differences in the effects of the criteria are clear. Plumes are entrained at much lower wind speeds with the upgraded model criteria.

Sector annual average normalized concentration estimates from the Regulatory Guide Split-H model are compared with those from the upgraded model using Equation (6) entrainment criteria in Figures 8 through 12 . A vent diameter of $2 \mathrm{~m}$ is assumed in each of the figures. The difference between the figures is the distance from the release. This distance varies from $400 \mathrm{~m}$ in Figure 8 to $6,400 \mathrm{~m}$ in Figure 12. Each of the figures compares concentration estimates for effluent vertical velocities of 5,10 and $20 \mathrm{~m} / \mathrm{s}$.

The figures show that increasing vertical velocity decreases the concentrations, as would be expected. They also show that the vertical velocity affects the difference between the models. At close-in distances, the greatest differences are found for a vertical velocity of $10 \mathrm{~m} / \mathrm{s}$. For a $5 \mathrm{~m} / \mathrm{s}$ vertical velocity, the differences tend to be smaller because there are few elevated plumes using either set of entrainment criteria, while for a $20 \mathrm{~m} / \mathrm{s}$ vertical velocity, there are relatively few entrained plumes.

As the distance from the source increases, the differences between the estimates from the models decrease. At $400 \mathrm{~m}$, the concentration estimates from the upgraded model are frequently a factor of 5 to 10 greater than those from the Regulatory Guide model for vertical velocities of 5 and $10 \mathrm{~m} / \mathrm{s}$. At a distance of $1,600 \mathrm{~m}$, the differences are mostiy a factor of 2 to 5 for the same vertical velocities, and at $6,400 \mathrm{~m}$, they are generally less than a factor of 2. This result was anticipated in the discussion of Figures 3 and 4.

Assuming that the meteorological data selected for the comparison studies represent a reasonable cross section of the relationships between wind speed and stability at reactor sites, the comparisons can be averaged over all sites to give typical values for the ratio of concentration estimates between different models.

Table 2 gives the range and geometric mean of ratios between the upgraded Split-H model and the Regulatory Guide model for an effluent vertical velocity of $10 \mathrm{~m} / \mathrm{s}$ as a function of stack diameter and downwind distance. Both the range of ratios and the geometric mean ratio decrease as the vent diameter and downwind distance increase. This is an indication that low flow rates, as determined from vertical velocity and diameter, contribute to discrepancies between the two Split-H models.

When the annual average concentrations estimated using upgraded Split-H models with the entrainment criteria in Equations (6) and (7) were compared, the differences were small. The average ratio between the concentrations for the 




FIGURE 8. Comparison of Ground-Level, Normalized Annual Average Concentrations at $400 \mathrm{~m}$ Estimated Using the Upgraded and Regulatory Guide 1.111 Split-H Models 


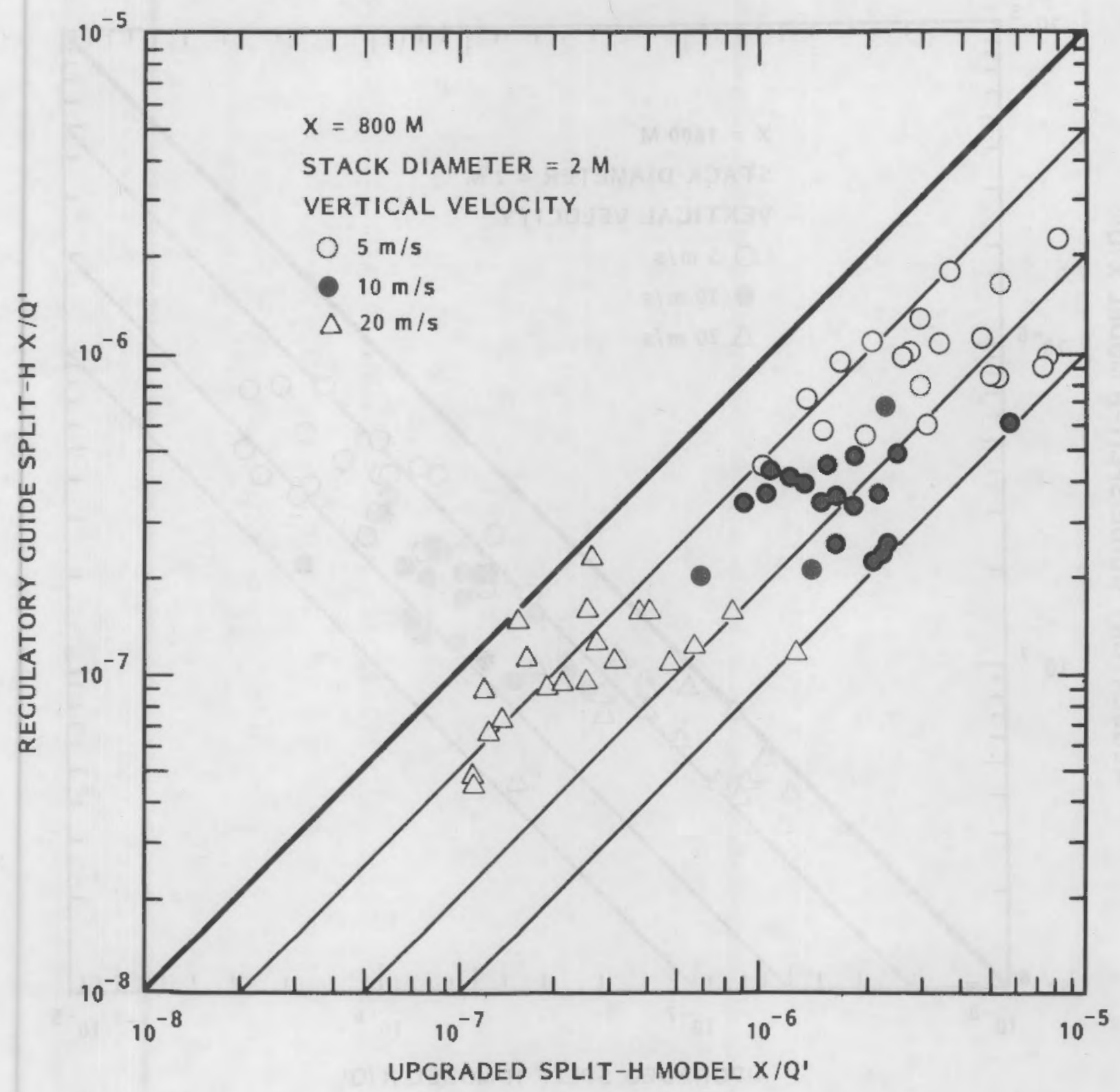

FIGURE 9. Comparison of Ground-Level, Normalized Annual Average Concentrations at $800 \mathrm{~m}$ Estimated Using the Upgraded and Regulatory Guide 1.111 Split-H Models 


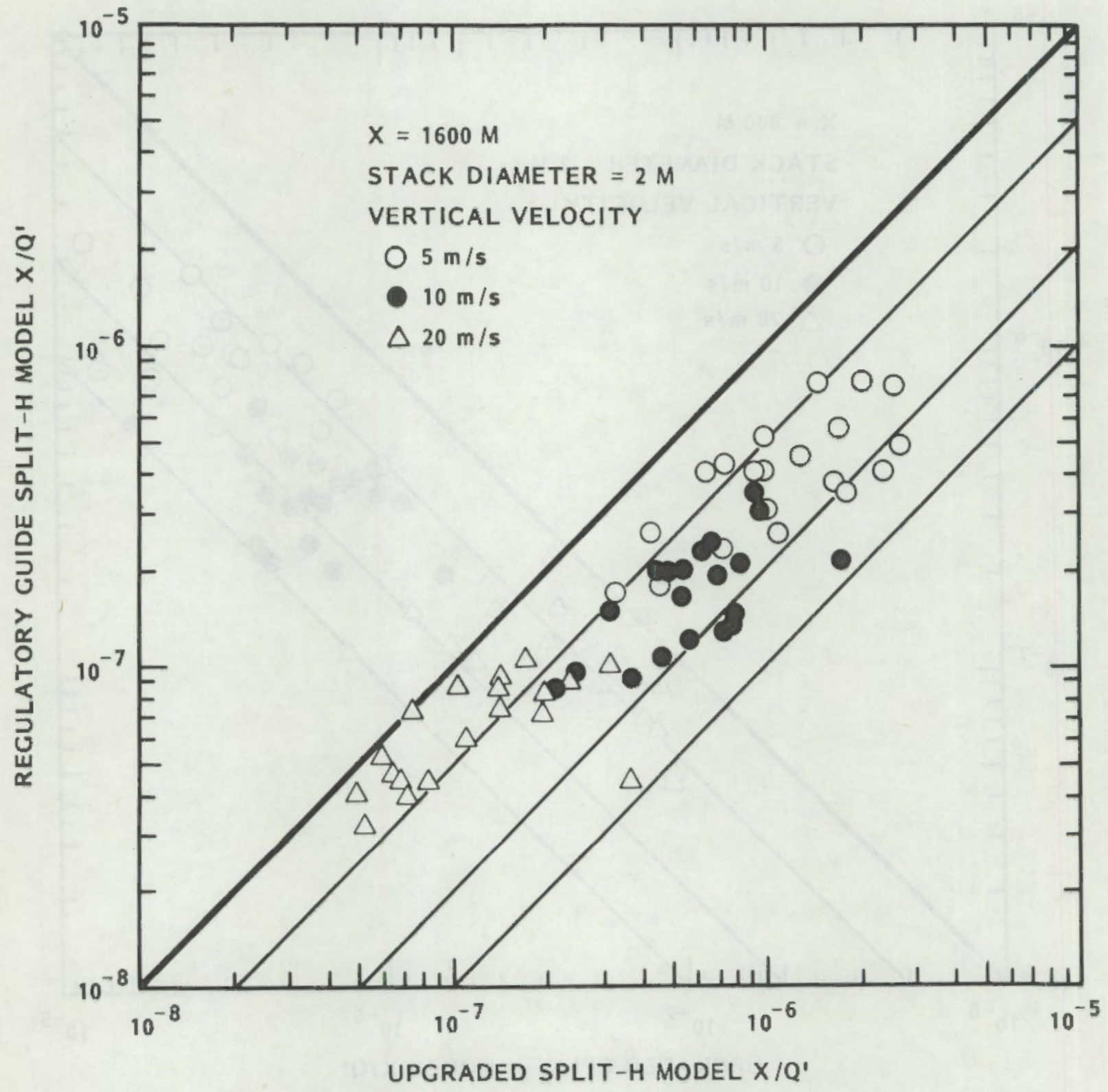

FIGURE 10. Comparison of Ground-Level, Normalized Annual Average Concentrations at $1600 \mathrm{~m}$ Estimated Using the Upgraded and Regulatory Guide 1.111 Split-H Models 


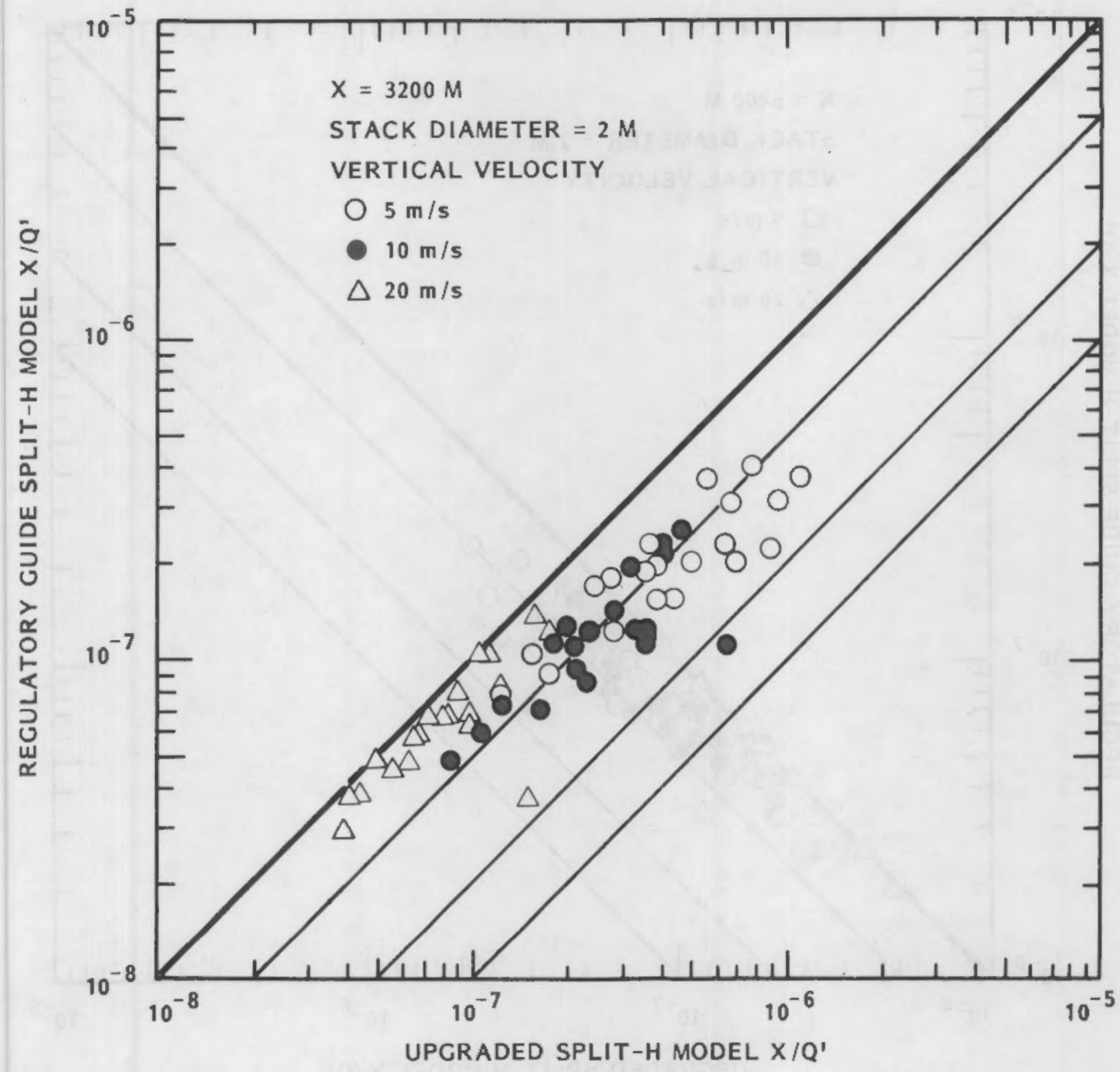

FIGURE 11. Comparison of Ground-Level, Normalized Annual Average Concentrations at $3200 \mathrm{~m}$ Estimated Using the Upgraded and Regulatory Guide 1.111 Split-H Models 


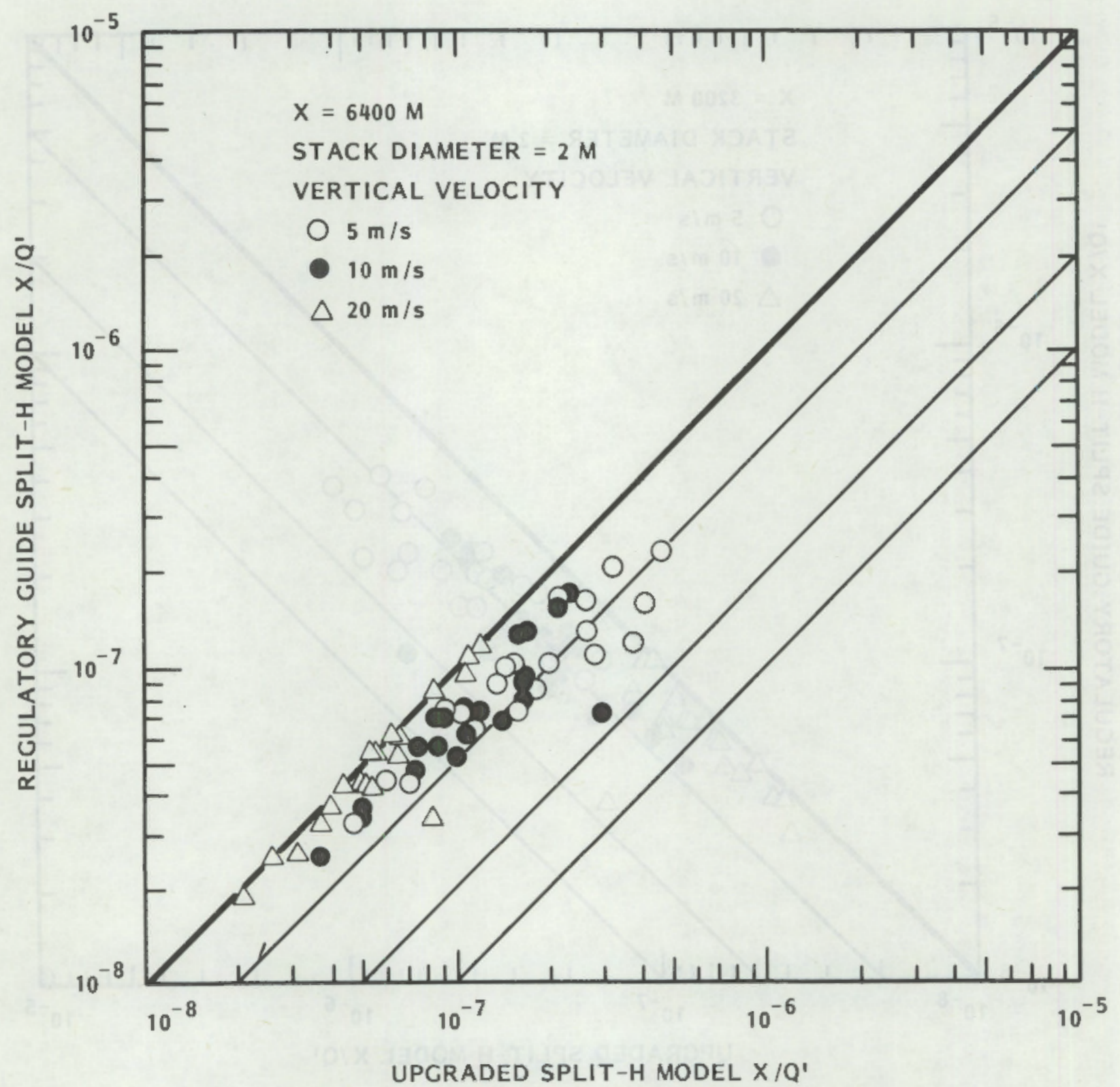

FIGURE 12. Comparison of Ground-Level, Normalized Annual Average Concentrations at $6400 \mathrm{~m}$ Estimated Using the Upgraded and Regulatory Guide 1.111 Split-H Models 
TABLE 2. Maximum, Geometric Mean and Minimum Ratios of Annual Average Concentrations (Upgraded/Regulatory Guide) for an Effluent Vertical Velocity of $10 \mathrm{~m} / \mathrm{s}$

\begin{tabular}{|c|c|c|c|c|c|}
\hline \multirow{2}{*}{$\begin{array}{c}\text { Distance } \\
(\mathrm{m})\end{array}$} & & \multicolumn{4}{|c|}{ Stack Diameter (m) } \\
\hline & & 1.41 & 2.00 & 2.82 & 4.00 \\
\hline 400 & $\begin{array}{l}\max \\
\text { g.m. } \\
\text { min }\end{array}$ & $\begin{array}{r}38.02 \\
8.54 \\
3.36\end{array}$ & $\begin{array}{r}11.44 \\
5.43 \\
2.67\end{array}$ & $\begin{array}{l}6.01 \\
2.77 \\
1.65\end{array}$ & $\begin{array}{l}2.64 \\
0.98 \\
0.36\end{array}$ \\
\hline 800 & $\begin{array}{l}\max \\
\mathrm{g} \cdot \mathrm{m} . \\
\min \end{array}$ & $\begin{array}{r}18.98 \\
6.79 \\
2.96\end{array}$ & $\begin{array}{l}9.18 \\
4.69 \\
2.38\end{array}$ & $\begin{array}{l}5.89 \\
2.47 \\
1.50\end{array}$ & $\begin{array}{l}2.61 \\
1.01 \\
0.59\end{array}$ \\
\hline 1600 & $\begin{array}{l}\max \\
\text { g.m. } \\
\text { min }\end{array}$ & $\begin{array}{l}9.85 \\
4.65 \\
2.40\end{array}$ & $\begin{array}{l}8.12 \\
3.49 \\
2.14\end{array}$ & $\begin{array}{l}5.46 \\
2.08 \\
1.32\end{array}$ & $\begin{array}{l}2.48 \\
1.00 \\
0.67\end{array}$ \\
\hline 3200 & $\begin{array}{l}\max \\
\text { g.m. } \\
\text { min }\end{array}$ & $\begin{array}{l}6.62 \\
2.62 \\
1.78\end{array}$ & $\begin{array}{l}5.80 \\
2.13 \\
1.56\end{array}$ & $\begin{array}{l}4.22 \\
1.53 \\
1.12\end{array}$ & $\begin{array}{l}2.15 \\
1.04 \\
0.90\end{array}$ \\
\hline 6400 & $\begin{array}{l}\max \\
\text { g.m. } \\
\text { min }\end{array}$ & $\begin{array}{l}4.54 \\
1.89 \\
1.39\end{array}$ & $\begin{array}{l}4.10 \\
1.62 \\
1.26\end{array}$ & $\begin{array}{l}3.15 \\
1.29 \\
1.05\end{array}$ & $\begin{array}{l}1.81 \\
1.04 \\
0.97\end{array}$ \\
\hline
\end{tabular}

two sets of criteria was 0.98 , with the simple criteria in Equation (7) giving slightly smaller values. It is unlikely that the differences in annual average concentrations estimated with these criteria are statistically significant.

\section{UPGRADED SPLIT-H MODEL RESULTS}

To examine the effect of the upgraded Split- $\mathrm{H}$ model on the annual average concentration, a $X / Q^{\prime}$ reduction factor was computed. The reduction factor, $R$, is the ratio between the annual average concentration estimated using the upgraded Split-H model and the concentration estimated using the ground-level, building wake plume model.

When the reduction factors for the upgraded Split-H model are grouped by vent flow rate, they show an exponential decrease as a function of the ratio between the effluent vertical velocity and the sector annual average wind speed. This decrease is illustrated in Figures 13 and 14 for flows of 15.7 and $31.4 \mathrm{~m} 3 / \mathrm{s}$. It is interesting to note that the reduction factors for vertical velocities of 5,10 and $20 \mathrm{~m} / \mathrm{s}$ fall along the same curve, as 1 ong as the flow rate remains constant. This feature was found for low flow rates and 




FIGURE 13. Variation of $X / Q^{\prime}$ Reduction Factor at $400 \mathrm{~m}$ with $W_{0} / \bar{U}$ for a Flow of $15.7 \mathrm{~m}^{3} / \mathrm{s}$ 


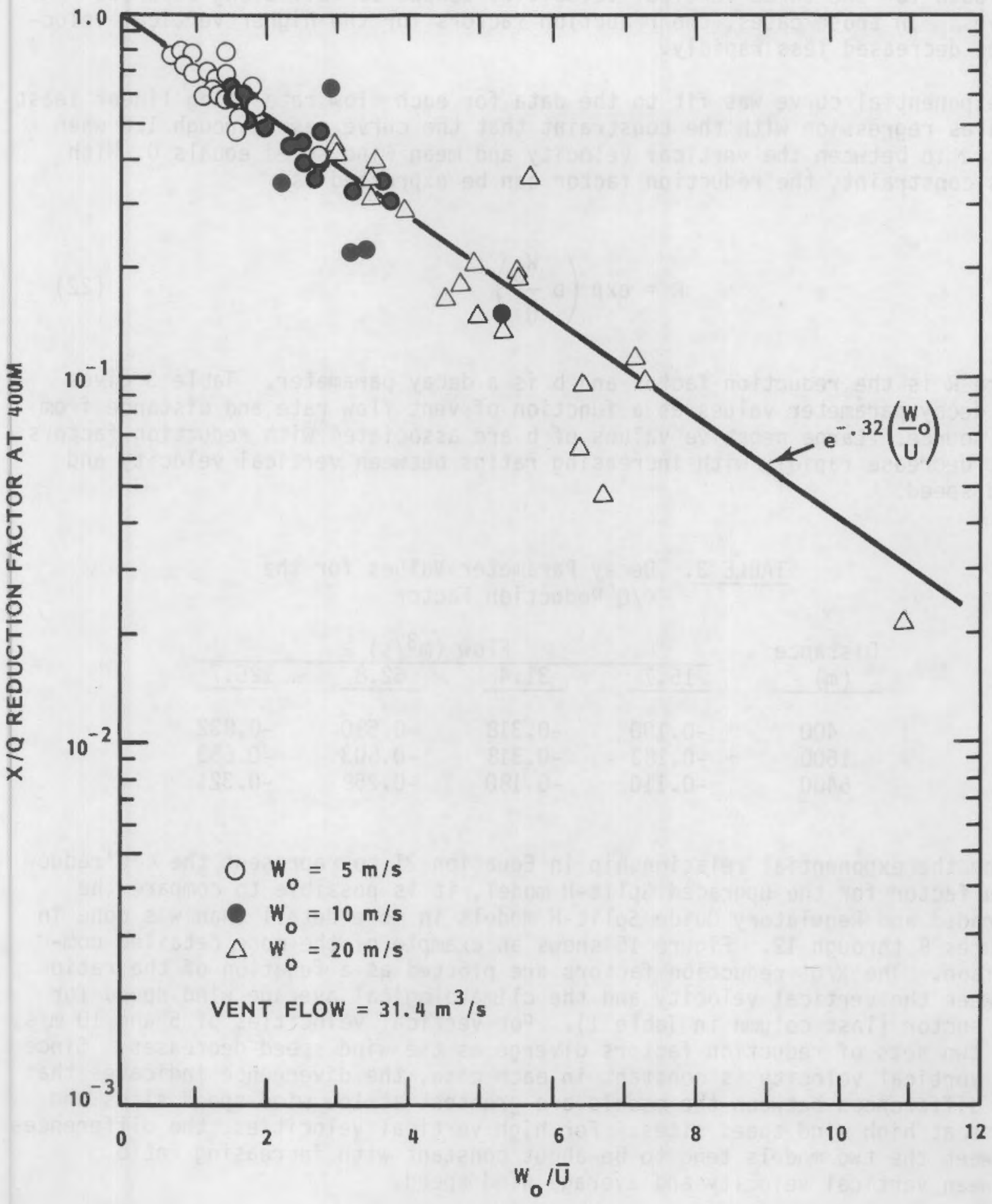

FIGURE 14. Variation of $X / Q^{\prime}$ Reduction Factor at $400 \mathrm{~m}$ with $W_{0} / \bar{U}$ for a Flow of $31.4 \mathrm{~m}^{3} / \mathrm{s}$ 
close in distances. At high flows $\left(125 \mathrm{~m}^{3} / \mathrm{s}\right)$ and large distances $(6400 \mathrm{~m})$, the data for the three vertical velocities tended to fall along separate curves. In those cases, the reduction factors for the higher vertical velocities decreased less rapidly.

An exponential curve was fit to the data for each flow rate using linear least. squares regression with the constraint that the curve pass through 1.0 when the ratio between the vertical velocity and mean wind speed equals 0 . With this constraint, the reduction factor can be expressed as

$$
R=\exp \left(b \frac{W_{0}}{\bar{U}}\right)
$$

where $R$ is the reduction factor and $b$ is a decay parameter. Table 3 gives the decay parameter values as a function of vent flow rate and distance from the source. Large negative values of $b$ are associated with reduction factors that decrease rapidly with increasing ratios between vertical velocity and wind speed.

TABLE 3. Decay Parameter Values for the $X / Q^{\prime}$ Reduction Factor

\begin{tabular}{|c|c|c|c|c|}
\hline \multirow{2}{*}{$\begin{array}{l}\text { Distance } \\
\text { (m) }\end{array}$} & \multicolumn{4}{|c|}{ Flow $\left(\mathrm{m}^{3} / \mathrm{s}\right)$} \\
\hline & 15.7 & 31.4 & 62.8 & 125.7 \\
\hline $\begin{array}{r}400 \\
1600 \\
6400\end{array}$ & $\begin{array}{l}-D .190 \\
-0.183 \\
-D .110\end{array}$ & $\begin{array}{l}-0.318 \\
-0.318 \\
-0.180\end{array}$ & $\begin{array}{l}-0.580 \\
-0.503 \\
-0.258\end{array}$ & $\begin{array}{l}-0.832 \\
-0.653 \\
-0.321\end{array}$ \\
\hline
\end{tabular}

Using the exponential relationship in Equation 21 to represent the $X / Q$ 'reduction factor for the upgraded Split-H model, it is possible to compare the upgraded and Regulatory Guide Split-H models in more detail than was done in Figures 8 through 12. Figure 15 shows an example of the more detailed comparison. The $X / Q^{\prime}$ reduction factors are plotted as a function of the ratio between the vertical velocity and the climatological average wind speed for the sector (last column in Table 1). For vertical velocities of 5 and $10 \mathrm{~m} / \mathrm{s}$, the two sets of reduction factors diverge as the wind speed decreases. Since the vertical velocity is constant in each case, the divergence indicates that the differences between the models are greatest at low wind speed sites and least at high wind speed sites. For high vertical velocities, the differences between the two models tend to be about constant with increasing ratio between vertical velocity and average wind speed. 


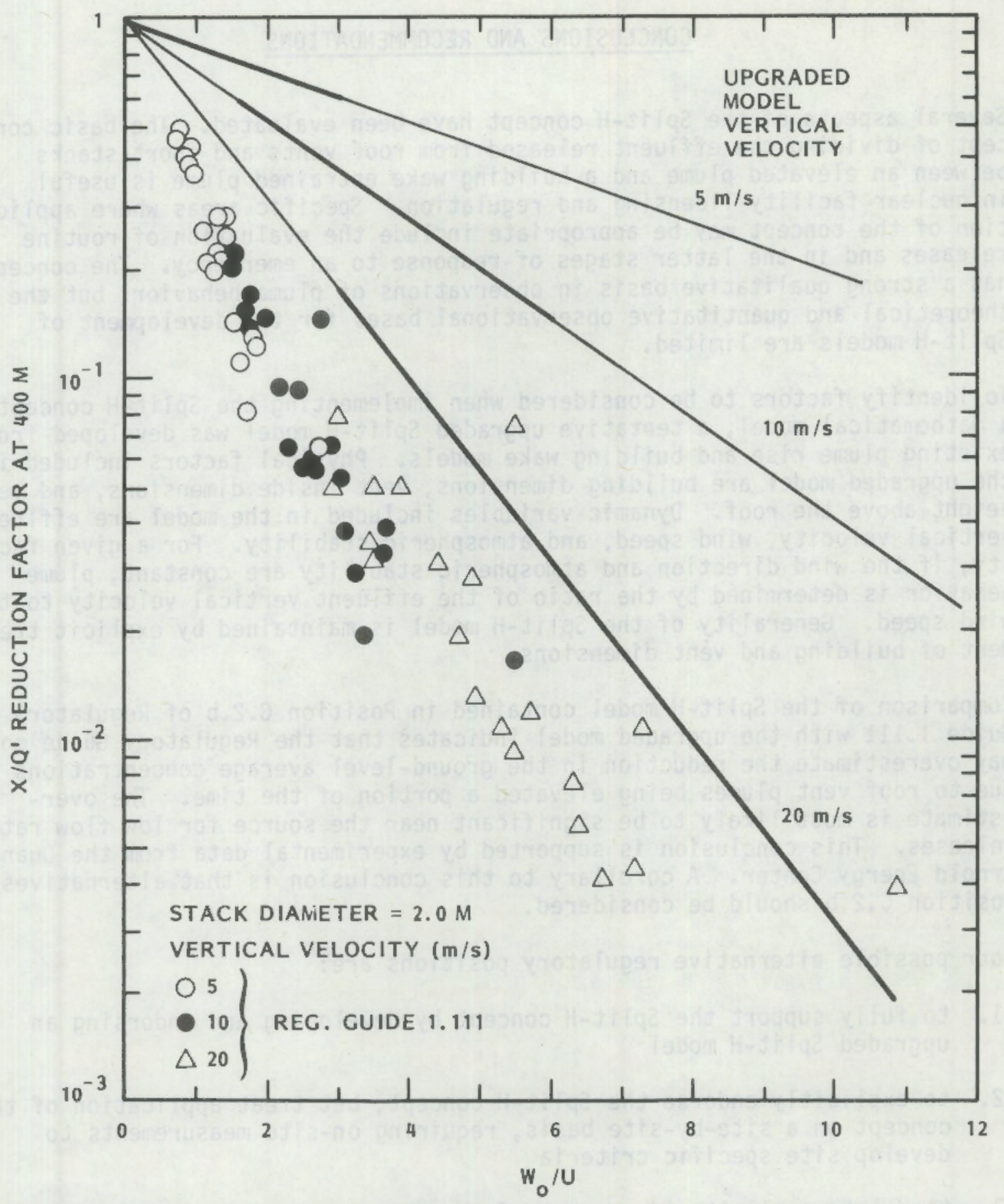

FIGURE 15. Comparison of $X / Q^{\prime}$ Reduction Factors for the Upgraded and Regulatory Guide 1.111 Split-H Models. The upgraded model estimates are shown as curves and the Regulatory Guide model estimates are shown as points. 
Several aspects of the Split-H concept have been evaluated. The basic concept of dividing the effluent released from roof vents and short stacks between an elevated plume and a building wake entrained plume is useful in nuclear facility licensing and regulation. Specific areas where application of the concept may be appropriate include the evaluation of routine releases and in the latter stages of response to an emergency. The concept has a strong qualitative basis in observations of plume behavior, but the theoretical and quantitative observational bases for the development of Split-H models are limited.

To identify factors to be considered when implementing the Split-H concept in a mathematical model, a tentative upgraded Split-H model was developed from existing plume rise and building wake models. Physical factors included in the upgraded model are building dimensions, vent inside dimensions, and vent height above the roof. Dynamic variables included in the model are effluent vertical velocity, wind speed, and atmospheric stability. For a given facility, if the wind direction and atmospheric stability are constant, plume behavior is determined by the ratio of the effluent vertical velocity to the wind speed. Generality of the Split-H model is maintained by explicit treatment of building and vent dimensions.

Comparison of the Split-H model contained in Position C.2.b of Regulatory Guide 1.111 with the upgraded model indicates that the Regulatory Guide model may overestimate the reduction in the ground-level average concentrations due to roof vent plumes being elevated a portion of the time. The overestimate is most likely to be significant near the source for low flow rate releases. This conclusion is supported by experimental data from the Duane Arnold Energy Center. A corollary to this conclusion is that alternatives to Position C.2.b should be considered.

Four possible alternative regulatory positions are:

1. to fully support the Split-H concept by developing and endorsing an upgraded Split-H model

2. to explicitly endorse the Split-H concept, but treat application of the concept on a site-by-site basis, requiring on-site measurements to develop site specific criteria

3. to delete explicit endorsement of the concept, but remain receptive to its application on a site-by-site basis

4. to delete explicit endorsement of the concept and reject any attempt to apply the concept. 
of these possibilities, the first and last represent the extreme positions. As a minimum, the first would require extensive re-analysis of existing data, and it is likely that it would require additional data collection. The last possibility represents a significant retreat from the current regulatory position and is probably unwarranted because of the qualitative but strong observational basis for the concept.

The second and third alternative positions are retreats from the current position, but leave room for flexibility by the Nuclear Regulatory Commission staff. The third alternative is essentially a return to an earlier regulatory position.

Finally, the second alternative represents an intermediate stance between the current position and alternative three. If the second alternive is adopted, the endorsement of the Split-H concept should be accompanied by a thorough discussion of the data to be required from an applicant before implementation of a Split-H model is approved.

Modification of the current regulatory position appears to be appropriate after considering: the utility of and bases for the concept, the possible implementation of the concept in a generally applicable Split-H model and the current regulatory position. Of the remaining alternatives, the first would be, by far, the most expensive. Therefore, adoption of the second or third alternative is recommended. The second alternative is preferred because it may provide additional incentive for the nuclear industry to collect the data that could support the development and application of a general Split-H model.

Until the Split-H approach in Position C.2.b is modified, the data in Tables 2 and 3 can be used to obtain a "feel" for the potential magnitudes of under estimates of the annual average concentration possible with the Regulatory Guide approach. 



\section{REFERENCES}

Batchelor, G. K. 1970. An Introduction to Fluid Dynamics. Cambridge University Press, London, UK.

Bird, R. B., W. E. Stewart, and E. N. Lightfoot. 1960. Transport Phenomena. Wiley, New York, NY.

Briggs, G.A. 1969. Plume Rise. USAEC Critical Review Series, TID-25075.

- 1975. "Plume Rise Predictions. "In Lectures on Air Pollution and Environmental Impact Analyses. Workshop Proceedings, American Meteorologi cal Society, Boston, MA.

Csanady, G. T. 1973. Turbulent Diffusion in the Environment. D. Reidel, Boston, MA.

Culkowski, W. M., 1967. "Estimating the Effect of Buildings on Plumes from Short Stacks." Nucl. Saf. 8:257-259.

Davies, P. 0. A. L., and D. J. Moore. 1964. "Experiments on the Behavior of Effluent Emitted from Stacks at or Near the Roof Level of Tall Reactor Buildings. Int. J. Air Wat. Poll. 8:515-533.

Halitsky, J. 1968. "Gas Diffusion Near Buildings," In Meteorology and Atomic Energy--1968. D. S1ade ed., TID-24190, USAEC. Pp. 221-255.

Hanna, S. R., G. A. Briggs, and R. P. Hosker, Jr. 1982. Handbook on Atmospheric Diffusion. DOE/TIC-11223, U.S. Department of Energy.

Hanzevack, E. L. 1982. "Dispersion from Safety Valves and Other Momentum Emission Sources: Continuous." Atmos. Environ. 16:1231-1237.

Hinze, J. 0. 1957. Turbulence. McGraw-Hill, New York, NY.

Hosker, R. P., Jr. 1981. Methods for Estimating Wake Flow and Effluent Dispersion Near Simple Block-Like Buildings. NOAA Technical Memorandum ERL ARL-108, Atmospheric Turbulence and Diffusion Laboratory, Oak Ridge, TN,

Johnson, W. B., E. Shelar, R. E. Ruff, H.B. Singh, and L. Salas. 1975. Gas Tracer Study of Roof-Vent Effluent at Millstone Nuclear Power Station. AIF/NESP-007b, Atomic Industrial Forum, Inc., Washington, D.C.

Koga, D. J., and J. L. Way. 1979. "Effects of Stack Height and Position on Dispersion in Building Wakes." In Wind Engineering, Proceedings of the Fifth International Conference. Ft. Collins, C0, Pp. 1003-1017.

Lawson, T. V. 1967. "Discussion of Papers--Turbulence and Diffusion in the Wake of a Building." Atmos. Environ. 1:177-181. 
Martin, J. E. 1965. The Correlation of Wind Tunnel and Field Measurements Using Krypton-85 as a Tracer. MMPP 272. University of Michigan, Ann Arbor. MI.

Meroney, R. N., J. E. Cermak, and F. H. Chaudhry. 1968. Wind-Tunnel Model Study of Shoreham Nuclear Power Station Unit I Long Island Lighting Company. CER68-69RNM-JEC-FHC1, Colorado State University, Ft. Collins, C0.

Munn, R. E., and A. F. W. Cole. 1967. "Turbulence and Diffusion in the Wake of a Building." Atmos. Environ. 1:33-43.

Papoul is, A. 1965. Probability, Random Variables, and Stochastic Processes. McGraw-Hill, New York, NY.

Philadelphia Electric Company. 1974. "Unit 2 Vent Plume Behavior--Peach Bottom Atomic Power Station." Docket Numbers 50-277 and 50-278. U.S. Nuclear Regulatory Commission.

Rodl iffe, R. S., and A. J. Fraser. 1971. "Measurements on the Release of Gaseous Activity from a Short Stack." Atmos. Environ. 몰 193-208.

Sagendorf, J. F., N. R. Ricks, G. E. Start, and C. R. Dickson. 1980. Diffusion Near Buildings as Determined from Atmospheric Tracer Experiments. NOAA Technical Memorandum ERL ARL-84, Air Resources Laboratory, Idaho Falls, ID.

Schlichting, H. 1968. Boundary-Layer Theory. McGraw-Hill, New York, NY. Scorer, R. S. 1958, Natural Aerodynamics. Pergamon Press, New York, NY. 1: $198-220$.

Slade, D. H., ed. 1968. Meteorology and Atomic Energy--1968. TID-24190, U.S. Atomic Energy Commission.

Smith, M. E. ed. 1968. Recommended Guide for the Prediction of the Dispersion of Airborne Effluents. American Society of Mechanical Engineers, New York, NY.

Thuillier, R. H. and R. L. Mancuso. 1980. Building Effects on Effluent Dispersion from Roof Vents at Nuclear Power Plants. EPRI NP-1380, Electric Power Research Institute, PaTo Alto, CA.

U.S. Nuclear Regulatory Commission. 1977. "Methods for Estimating Atmospheric Transport and Dispersion of Gaseous Effluents in Routine Releases from Light-Water-Cooled Reactors." Regulatory Guide 1.111, Revision 1, Washington, D.C.

U.S. Weather Bureau. 1953. A Meteorological Survey of the Oak Ridge Area: Final Report Covering the Period 1948-52. USAEC Report ORO-99, Oak Ridge, TN. 
Wilson, D. J. 1979a. Height and Location of Exhaust Stacks to Reduce Recirculation to Air Intakes. ASHRAE final report RP204.

- 1979b. "Flow Patterns Over Flat-Roofed Buildings and Application to Exhaust Stack Design." ASHRAE Trans. 85 part 2:284-295. 



\section{$\underline{\text { DISTRIBUTION }}$}

No. of

Copies

OFFSITE

U.S. Nuclear Regulatory Commission

Division of Technical Information and Document Control

DOE Technical Information Center

Mr. J. Fairobent

Division of System Integration

Office of Nuclear Reactor Regulation

U.S. Nuclear Regulatory Commission

Washington, DC 20555

ONSITE

Pacific Northwest Laboratory

KJ Allwine

GF Athey

DW Dragnich

JC Doran

JG Droppo

CS GI antz

RK Hadlock

CG Lindsey

JV Ramsdell (10)

WF Sandusky

CD Whiteman

Publishing Coordination (2)

Technical Information (5) 



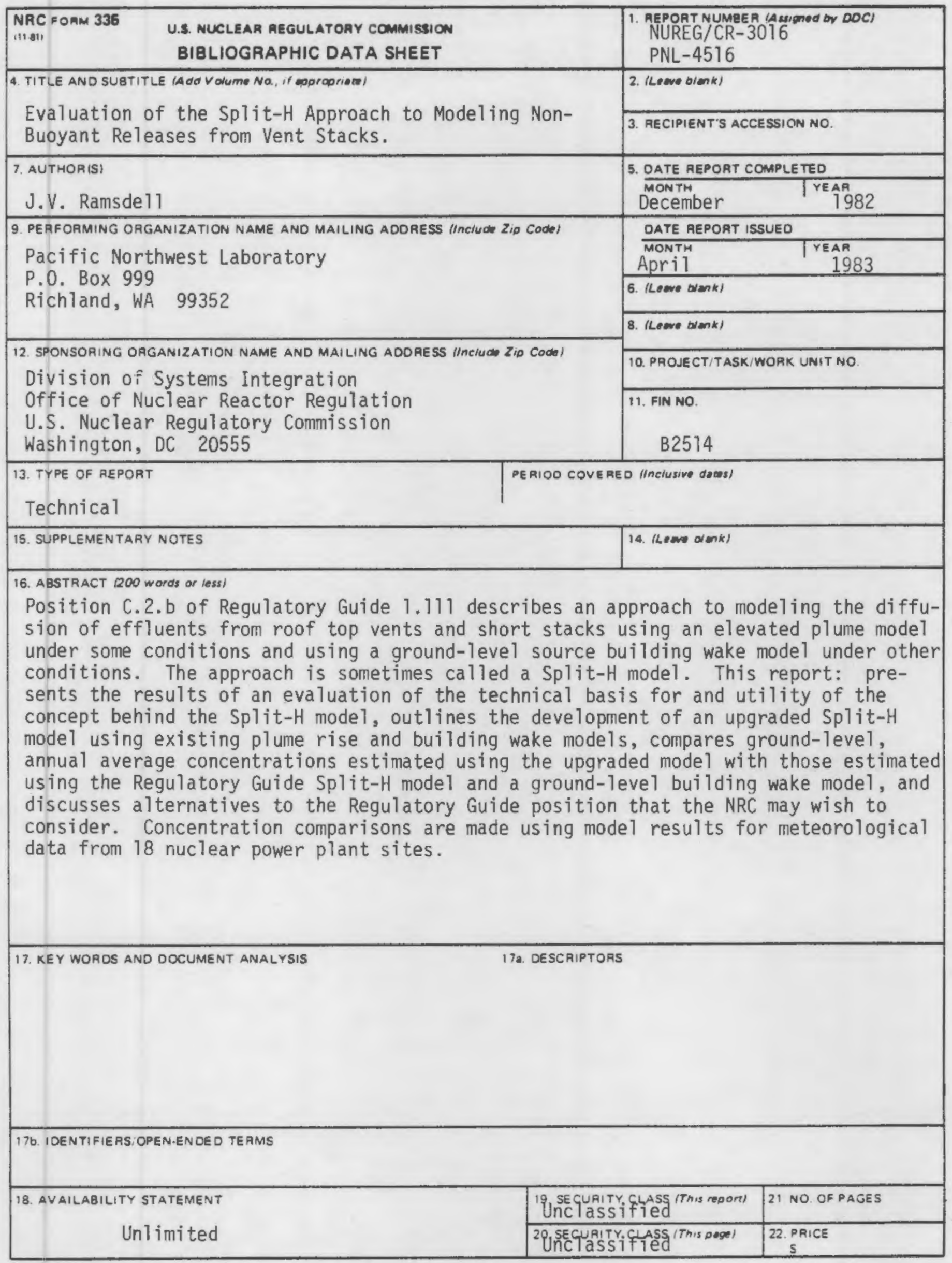




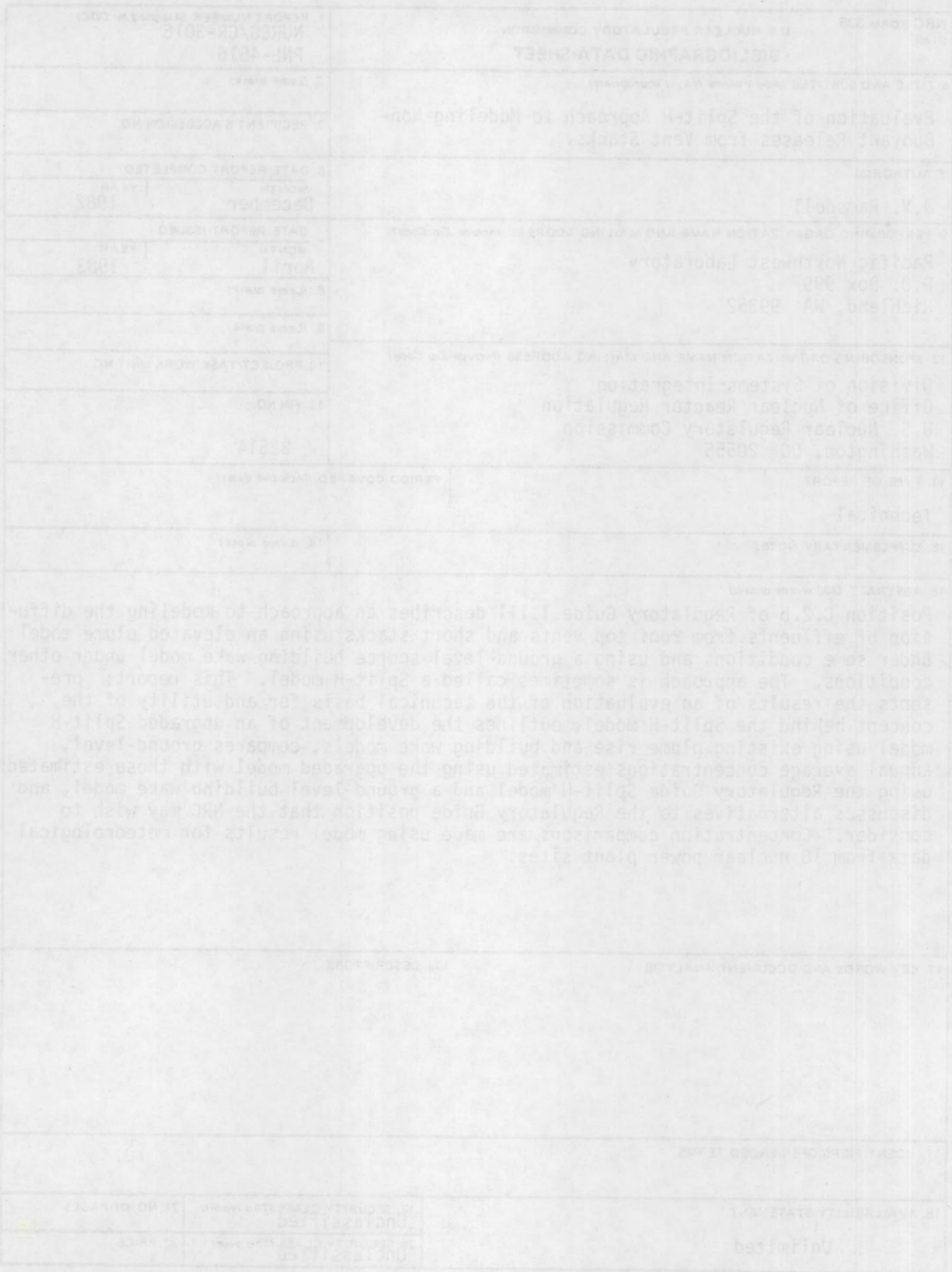

